\title{
LONG-TERM PATTERNS OF AIR TEMPERATURES, DAILY TEMPERATURE RANGE, PRECIPITATION, GRASS-REFERENCE EVAPOTRANSPIRATION AND ARIDITY INDEX IN THE USA Great Plains: PART II. TEMPORAL TrENDS
}

\author{
M. Kukal and S. Irmak* \\ University of Nebraska-Lincoln, 239 L.W. Chase Hall, Lincoln, NE. \\ ${ }^{*}$ Corresponding author (Suat Irmak). Address: \\ University of Nebraska-Lincoln. 239 L.W. Chase Hall, Lincoln, NE 68583. \\ Tel.: (402) 472-4865. E-mail address: sirmak2@unl.edu.
}

\begin{abstract}
Detection of long-term changes in climate variables over large spatial scales is a very important prerequisite to the development of effective mitigation and adaption measures for the future potential climate change and for developing strategies for future hydrologic balance analyses under changing climate. Moreover, there is a need for effective approaches of providing information about these changes to decision makers, water managers and stakeholders to aid in efficient implementation of the developed strategies. This study involves computation, mapping and analyses of long-term (19682013) county-specific trends in annual, growing-season ( $1^{\text {st }}$ May- $30^{\text {th }}$ Sept.) and monthly air temperatures $\left[\left(\right.\right.$ maximum $\left(T_{\max }\right)$, minimum $\left(T_{\min }\right)$ and average $\left.\left(T_{\text {avg }}\right)\right]$, daily temperature range $(D T R)$, precipitation, grass reference evapotranspiration $\left(E T_{o}\right)$ and aridity index (AI) over the USA Great Plains region using datasets from over 800 weather station sites. Positive trends in annual $T_{\text {avg, }}, T_{\max }$ and $T_{\min }$, DTR, precipitation, $E T_{o}$ and AI were observed in $71,89,85,31,61,38$ and $66 \%$ of the counties in the region, respectively, whereas these proportions were 48, 89,62,20,57,28, and 63\%, respectively, for the growing-season averages of the same variables. On a regional average basis, the positive trends in growing-season $T_{\text {avg }}, T_{\max }$ and $T_{\min }, D T R$, precipitation, $E T_{o}$ and $A I$ were $0.18^{\circ} \mathrm{C}_{\text {decade }}{ }^{-1}, 0.19^{\circ} \mathrm{C}_{\text {decade }}^{-}$ ${ }^{1}, 0.17^{\circ} \mathrm{C}_{\text {decade }}{ }^{-1}, 0.09^{\circ} \mathrm{C}$ decade ${ }^{-1}, 1.12 \mathrm{~mm} \mathrm{yr}^{-1}, 0.4 \mathrm{~mm} \mathrm{yr}^{-1}$ and 0.02 decade ${ }^{-1}$, respectively, and the negative trends were $0.21^{\circ} \mathrm{C}$ decade $e^{-1}, 0.06^{\circ} \mathrm{C}_{\text {decade }}{ }^{-1}, 0.09^{\circ} \mathrm{C}$ decade ${ }^{-1}, 0.22^{\circ} \mathrm{C}_{\text {decade }}$, $1.16 \mathrm{~mm} \mathrm{yr}^{-1}$, $0.76 \mathrm{~mm} \mathrm{yr}^{-1}$ and 0.02 decade ${ }^{-1}$, respectively. The temporal trends were highly variable in space and were appropriately represented using monthly, annual and growing-season maps developed using Geographic Information System (GIS) techniques. The long-term and spatial and temporal information and data for a large region provided in this study can be used to analyze county-level trends in important climatic/hydrologic variables in context of climate change, water resources, agricultural and natural resources response to climate change. Keywords. Climate variables, spatial, temporal, air temperature, daily temperature range, precipitation, aridity index, evapotranspiration.
\end{abstract}

\section{INTRODUCTION}

The Fourth Assessment Report of the United Nations Intergovernmental Panel on Climate Change (IPCC, 2007) established that there has been a warming effect in our climate system during the recent decades. Moreover, Fifth Assessment Report (IPCC, 2013) stated that for the average annual Northern Hemisphere temperatures, the period of 1983-2012 was the warmest 30-year span over the last 800 years. During the last century, the air temperature at the earth's surface rose by $0.74^{\circ} \mathrm{C}$ and this increase was attributed to the increase in the concentrations of the greenhouse gases in the atmosphere. 
Despite the large uncertainties in the projections of future temperature, the IPCC global climate models show that the warming trends will continue. This warming induces hydroclimatic changes and intensifications in hydrological cycles and results in alteration of several processes such as precipitation, runoff, infiltration, groundwater flow, soil moisture and evapotranspiration in different ways (Huntington, 2006). These changes would possibly vary to a large extent across any one continent (Ziegler et al., 2005), and because of this, it is challenging to extrapolate any trends in the climatic variables from one geographical location to another, even on an intra-continental scale. In such a dynamic climate system, it is of the utmost importance to study the long-term impacts of climate change on hydrological and meteorological elements at extensive scales across the globe. Researchers (Zhang et al., 2001; Kahya and Kalayci, 2004; Lins and Slack, 2005; Aziz and Burn, 2006; Burn 2008; Jhajharia et al., 2009; Sahoo and Smith, 2009; Deni et al., 2010; Irmak et al., 2012) have investigated the trends in hydro-metrological variables such as air temperature, precipitation, streamflow, drought characteristics and reference evapotranspiration at various locations across the world.

One of the most important variables that needs to be addressed in a complex meteorological/hydrological setting is the air temperature. As mentioned earlier, increasing temperature trends have been identified in several areas of the world, which vary in their magnitudes in both space and time. Irmak et al. (2012), in a study performed in Central Nebraska, USA, found out that during a 116year period, the minimum air temperatures showed a significant increasing trends, while maximum temperature showed non-significant decreasing trends. An interesting observation was that the decadal trends in observed temperatures were very different, when compared to those in the 116-year period, which implies substantial temporal variation. Similarly, Martinez et al. (2012) observed that in Florida, USA, maximum, minimum and mean air temperatures show an increasing trend in the period of 18952009. The trends in observed temperatures have also been shown to be impacted by regional land use/land cover. For example, Karl et al. (1993) observed that the maximum air temperatures decreased in all seasons except winter and the minimum air temperatures increased in all seasons as a result of 
urbanization. However, in a recent study by Mishra and Lettenmaier (2011), it has been shown that majority of the temperature trends were a result of the regional changes in climate rather than the local urbanization effects. Peterson et al. (2011) concluded that the land cover is instrumental in influencing surface moisture content, which subsequently can affect air temperature. Likewise, Lobell and Bonfills (2008) suggested that the conversion of natural land covers into irrigated agriculture tends to decrease surface temperature. Besides studies in USA, many other researchers conducted temperature trend assessments in other parts of the world namely Europe (Winkler, 2009; Bohm et al., 2010; Tietavainen et al., 2010; van der Schrier et al., 2011), China (Li et al., 2009; Zhen and Zhong-Wei, 2009; Li et al., 2010; Tang et al., 2010), India (Jain and Kumar, 2012), Australia (Trewin, 2012), Canada (Vincent et al., 2012), South America, (Falvey and Garreaud, 2009) and East Africa (Christy et al., 2009) and agree on rise in land surface air temperatures. In light of the above findings, it is clear that the observed temperature trends are highly variable in both space and time and intensive attempts are necessary to investigate, quantify and analyze these trends accordingly.

Precipitation is widely involved in meteorological and hydrological processes and is a crucial element of the agricultural and natural resource water balances. Studies conducted imply that the global terrestrial precipitation has increased during the $20^{\text {th }}$ century (IPCC, 2007). But, similar to temperature, there can be substantial spatial and temporal variability in the global precipitation patterns. In fact, it is established that precipitation is one of the variables which is characterized by strong variability even on a small scale. For instance, the trends in annual precipitation in northern Europe have been found to be increasing, while showing a decreasing tendency in the Southern Europe (Schonwiese and Rapp, 1997). Irmak et al. (2012) found that in Central Nebraska, USA, there has been a significant increasing trend in annual precipitation, which amounts to an increase of $100 \mathrm{~mm}$ from 1893 to 2008 . The authors also stressed on the fact that the nature of the trend in annual total precipitation was negative until 1956 and became positive from 1956 to 2008. The Intergovernmental Panel on Climate Change- Assessment Report 5 (IPCC, 2013) presents evidence of increasing precipitation, especially in mid latitudes of the 
Northern Hemisphere with medium confidence since 1901, but high confidence after 1951. Changes in precipitation can result in changes in several other variables, especially atmospheric demand, thus necessitating the analysis of precipitation time-series in the areas of interest.

Evapotranspiration is a reliable indicator of climate change and hydrological cycle being the connecting process between energy balance and water balance (Xu and Singh, 2005). The importance of ET has motivated several researchers to identify the long-term trends in order to better understand the regional scale hydroclimatic trends (Roderick and Farquhar, 2002; Liu et al., 2004; Xu et al., 2006; Burn and Hesch, 2007; Liu and Yang., 2010; Irmak et al., 2010; Jung et al., 2010). It has been reported that reference ET, which is the atmospheric demand from a reference crop surface, has shown a decreasing trend in many areas of the world. For example, Irmak et al. (2012) showed that the reference ET decreased at a rate of $0.36 \mathrm{~mm} \mathrm{yr}^{-1}$ during 1893-2008 in Central Nebraska, USA. Similarly, there are numerous studies which observed similar negative trends such as USA (Peterson et al., 1995), former Soviet Union (Golubev et al., 2001), Italy (Moonen et al., 2002), Australia (Roderick and Farquhar, 2004), China (Liu et al., 2004), Thailand (Tebakari et al., 2005), Canadian Praries (Burn and Hesch, 2007) and India (Chattopadhyay and Hulme, 1997). The explanations provided by the authors for this behavior are inconsistent due to distinct study regions and approaches used and they insinuate that the changes are attributed to different meteorological factors in different regions because the impacts of these factors and their interactions can change substantially from one region to another and also within the same region temporally.

Another crucial implication among the warming-induced phenomena that needs to be discussed and further investigated is aridity or desertification. A large range of definitions/ indices for this term exists in the relevant literature in the context of varied disciplines such as climatology, soil science, hydrology, geomorphology and vegetation dynamics and which vary by the inclusion of several parameters and variables (Jain et al., 2010; Hasan and Murat, 2011; Lampros et al., 2011; Liu et al., 2012; Maliva and Missimer, 2012, Gao et al., 2015). This is a variable that can be affected by a combined role 
of natural and human-induced factors, among which the climatic change remains the main driving force (Dong, 2004). Several model scenarios were adopted by researchers in several parts of the world to predict humidity/aridity trends and found that drought conditions would continue in critical agricultural regions. Andreadis and Lettenmaier (2006) employed certain simulated hydro-climatological variables to analyze and investigate the drought characteristics for the $20^{\text {th }}$ century over the conterminous USA. They concluded that for the majority of the areas, the frequency of the droughts has decreased, along with shortening of their duration and the decrease in their areal extent. In Northwestern China, Wang et al. (2008) proposed an index relating aridity to wetness and observed that a humidification trend was discernible in the region. Other researchers (Yan and Yang, 2000; Zhai et al., 1999) attempted to rely on extreme precipitation to investigate the trends in extreme drought or wetness. To evaluate the aridity trends and its spatial patterns, it is important to employ suitable aridity indices to assess the magnitude of drought/wetness. The Food and Agriculture Organization (FAO) has recommended an aridity index (AI), which is expressed as the ratio of annual precipitation to annual potential (reference) evapotranspiration (Middleton and Thomas, 1992). The use of this form of the AI has been widespread by United Nations Educational, Scientific and Cultural Organization (UNESCO), Global Environmental Monitor System (GEMS), Global Resource Information Database (GRID). The annual potential evapotranspiration represents the evaporative demand of the atmosphere not being constrained by water availability in a given climate (McMahon et al., 2013). The AI, hence implies a quantitative indication of the degree of water vapor deficiency to meet the evaporation demand at a given geographical location (Fu and Feng, 2014).

The Great Plains of the USA, which is the most prime agriculturally-dominated region in the nation, hosts a population of 9.9 million people (as of 2007) (US Census Bureau, 2009). It has a high potential to serve as a very crucial region for investigative studies aimed at analyzing the spatial patterns, temporal trends, and spatial distribution of temporal trends. An approach aimed towards qualitative as well as a quantitative estimation of the trends of climatic variables would aid in providing fruitful insights 
into the long-term dynamics of temperature, precipitation, aridity and reference evapotranspiration in the region, which would aid to quantify the impact of climate change on the hydrological balance and improve our current and future management strategies. Studies which investigate long-term trends at large spatial scales such as Great Plains have been extremely scarce, although several studies have been conducted on statewide basis. Mutiibwa and Irmak (2013) discussed the effects of long-term irrigation practices on the evapotranspiration trends over the US High Plains. In the process, they quantified large scale reference ET trends, calculated by Hargreaves-Samani equation during the period 1968-2013, and found that there was no significant increasing or decreasing trend at any of the six sampled locations. In their study, trends at the locations where more than $90 \%$ land use is agricultural were analyzed, as they aimed at investigating the impacts of irrigation practices on air temperatures and ET. This current study, on the contrary, focuses on analyzing the trends on a county basis, thus including all geographical regions in any state of the region to provide a broader and comprehensive perspective on temporal trends. Sharma and Irmak (2012) carried out an analysis to quantify and analyze the spatial and temporal trends in precipitation and reference ET from 1986 to 2012 at all 93 counties in Nebraska, USA. Our study is based on similar approach but on a much wider geographical (9 states) and temporal scales (1968-2013) and attempting to strengthen the temporal trend analysis by integration of simple linear regression with more appropriate non parametric tests.

The growing season trends in air temperatures, precipitation and reference evapotranspiration have much more significance than annual trends in the context of agricultural practices, owing to the seasonal behavior of crops, quantification and allocation of irrigation and water resources. As a result, our study emphasizes the need for investigating growing-season trends for all of the aforementioned variables. Moreover, the study presents temporal trends on a monthly basis throughout the year, as trends during the non-growing season could be crucial for certain analyses as well. Since, the hydrological processes in the winter months influence the amount of soil moisture that may become available for crop uptake in the next growing season, it is equally important to quantify and analyze trends during the non- 
growing season months as well. Also, this period serves as the growing season for crops such as winter wheat and cover crops, which makes this analyses useful. Another interesting characteristic of the Great Plains region is that it encompasses areas with complex climatic conditions, ranging from arid, semi-arid zones in the West to dry sub humid and humid zones in the East. Because of this, it is expected that spatial heterogeneity in trends would be observed in this region. To identify these trends at appropriate scales, it is important to select spatial units to analyze these trends so that the spatial heterogeneity in them can be explored and quantified and regionalization of the trends can be analyzed and presented. For this purpose, several spatial units such as counties, states and climate divisions are employed in this study in order to report the trends at familiar scales so as to be easily used in other applications. Thus, the specific objectives of this study are to quantify regional scale precipitation, air temperatures, grassreference evapotranspiration $\left(\mathrm{ET}_{\mathrm{o}}\right)$ and aridity for USA Great Plains over a 46-year period (1968-2013) using available datasets. Mapping of each of these variables at monthly, growing-season $\left(1^{\text {st }}\right.$ May- $30^{\text {th }}$ September) and annual time ( $1^{\text {st }}$ January- $31^{\text {st }}$ December) steps are conducted. Spatial patterns and geographical distribution for each of the variables of interest are analyzed using GIS-assisted tools and visual aids. Further, the temporal trends over the entire period are explored and quantified at appropriate scales using both parametric and non-parametric statistical techniques with the emphasis that would also be laid on analyzing the spatial distribution of differential temporal trends over the study area.

\section{MATERIALS AND METHODS}

\section{STUdY AREA AND DATA SOURCES}

The study area (Great Plains, USA, Figure 1) and its characteristics were reported in detail by Kukal and Irmak (2016) (Part I of this study; this issue). The study uses spatial datasets of air temperatures, diurnal temperature range, precipitation, $\mathrm{ET}_{\mathrm{o}}$ and aridity index (AI) to extract time series of county-averaged variables for trend detection. These spatial datasets were developed from observed air temperature and precipitation data collected at 834 sites. Details about sources of data and procedures that 
were used for the development of spatial datasets were explained in detail by Kukal and Irmak (2016) (Part I of this study).

\section{EXTRACTION OF COUNTY-SPECIFIC VALUES}

The spatial interpolation process aids in determining values of the variables at all locations across the spatial extent of the Great Plains. The spatial and temporal analyses of trends within a single variable were carried out keeping in mind a relevant spatial unit. The spatial unit was selected so that its areal extent is relevant to the application of the information. For example, while studying environmental/climatic variables, climate divisions/zones can prove to be a useful spatial unit. In this study, we chose to consider counties as proper spatial units for the purpose of conducting all the spatial and temporal trend analyses. The 834 counties in the study region have an average terrestrial area of 2877 $\mathrm{km}^{2}$. Out of 834 counties, 534 counties $(64 \%)$ consist of one or more weather station sites. Despite the fact that $44 \%$ of the counties do not physically consist of weather stations with long-term data, it can be observed that the sites are evenly distributed on a geographic basis, which implies that spatial interpolation was performed with confidence and reasonable spatial estimations was achieved. Since the study focusses on exploring the spatial and temporal trends in the variables of interest in the context of agricultural production, counties were considered appropriate spatial units because of several reasons. Primarily, the consistency of the datasets developed in this study with the existing datasets was considered crucial. One such example is that the National Agricultural Statistics Service- United States Department of Agriculture (NASS-USDA) distributes the national agricultural production statistics for a wide range of crops on a county-level basis. Likewise, several other sets of information such as commodity prices, fertilizer inputs and management practices are reported on county-level basis. Thus, development of datasets for climate/ environmental/ hydrological variables on county basis results in increased potential for the application of these datasets to investigate the impacts of climate change on agricultural production and yields in the future. Moreover, county-level information of magnitudes and 
trends in these variables would be directly useful for state and federal agencies working in the discipline of natural resource conservation.

The consideration of counties as discrete spatial units necessitates the quantification of countyspecific values from the continuous gridded surfaces for each of the variables investigated. Using the previously developed [Kukal and Irmak (2016) (Part I of this study; this issue)] monthly raster surfaces for all the variables (namely precipitation, maximum, minimum and mean air temperatures) as inputs to a GIS-assisted tool [Zonal Statistics in ArcGIS 10.2], county-based values for the variables were computed using a county boundary dataset for the 9 states in the study area. The zonal statistics tool computes a broad range of statistics such as mean, maximum, minimum and range on the raster value for a zone of another dataset. These statistics, especially mean were calculated from the gridded rasters for each county in the study region. The tool performs this operation by summarizing the value of the raster within the zone (county) and reports the result as mean value of the raster within that particular zone. Several studies have used this function as a tool to obtain zonal values for a variety of zones and variables such as Normalized Difference Vegetation Index (Bakhsh and Kanwar, 2004) and crop yield (Kulkarni et al., 2008). Sharma and Irmak. (2012) used this procedure to compute precipitation and reference evapotranspiration for all 93 counties in Nebraska, USA.

\section{Statistical TREND ANALYSIS}

The county-specific values for all the variables were quantified throughout the 46-year study period and time-series constructed for each variable. In order to identify temporal trends in these variables, and to investigate their statistical significance, a certain set of statistical tests were applied. These principles and procedures for these tests are described in the next section.

\section{MANN-KENDALL TREND TEST AND SLOPE ESTIMATOR}

The Mann-Kendall (M-K) test, also referred to as Kendall's tau test, is one of the most widely accepted non- parametric tests to detect significant trends in a time-series (Mann, 1945) (Kendall, 1948). 
The null hypothesis $\left(H_{0}\right)$ stated by the $M-K$ test is that a sample of data $X=\left\{x_{i: i}=1,2, \ldots n\right\}, x_{i}$ is a sample of $n$ independent and identically distributed random variables. On the other hand, the alternative hypothesis $\mathrm{H}_{1}$ is that a monotonic trend exists in $\mathrm{X}$. The test statistic $\mathrm{S}$ is asymptotically normal, has a mean zero and a variance which is computed using following equations;

$$
S=\sum_{k=1}^{n-1} \sum_{j=k+1}^{n} \operatorname{sgn}\left(x_{i}-x_{j}\right)
$$

where, $x_{j}$ are the sequential data values, $n$ is the length of the dataset (number of data points).

$$
\operatorname{sgn}\left(x_{j}-x_{k}\right)=\left\{\begin{array}{l}
+1 \text { if }\left(x_{j}-x_{k}\right)>0 \\
0 \text { if }\left(x_{j}-x_{k}\right)=0 \\
-1 \text { if }\left(x_{j}-x_{k}\right)<0
\end{array}\right.
$$

where, $t$ represents the extent of a given tie, and $\Sigma_{t}$ is the summation over all ties. In cases where the sample size $n>10$, the standard normal variable $Z$ is computed using Eq. (4).

$$
\begin{cases}Z= & \text { if } \mathrm{S}>0 \\ 0 & \text { if } \mathrm{S}=0 \\ \frac{S+1}{\sqrt{\operatorname{Var}(S)}} & \text { if } \mathrm{S}<0\end{cases}
$$

Increasing trends are represented by positive values of $Z$, while decreasing trends are represented by negative values. In order to investigate the increasing or decreasing monotonic trends at the $\alpha$ significance level, the null hypothesis was rejected when the absolute value of $Z$ greater than $Z_{1-\alpha / 2}$ was 
detected, where $Z_{1-\alpha / 2}$ was obtained from the standard normal cumulative distribution tables. The detection of any increasing or decreasing trends in this study was performed at the significance level of $\alpha=0.05$.

After the establishment of the fact that a linear trend is present in a particular time-series, a simple non-parametric procedure developed by Sen (1968) can be applied to calculate the true magnitude of the slope of the linear trend. This estimate is given by the Theil-Sen Estimator as:

$$
b=\operatorname{Median}\left(\frac{x_{j}-x_{z}}{j-1}\right)
$$

Considering an annual time series, $b$ denotes the annual increment under the hypothesis of a linear trend. $b$ provides the real slope of the tendency, and can vary slightly from the slope obtained from linear regression.

\section{RESULTS}

\section{TRENDS IN AIR TEMPERATURES}

Maximum air temperature

Long term trends from 1968 to 2013 for maximum, minimum and average air temperatures for the 834 counties in the Great Plains of USA have been investigated using non-parametric tests. The trends in annual and growing-season maximum air temperatures are shown in Figure 2. The maps that are developed and presented here (and further in the manuscript) show the nature and statistical significance of the county-level trends in a particular variable during the study period. The blue upright arrows in the maps represent increasing (positive) trends, while the red inverted arrows indicate decreasing (negative) trends. Counties with green background indicate that the trend quantified for the county is statistically significant at $\alpha=0.05$, which distinguishes them from the counties with insignificant trends (counties assigned with a white background). Despite the fact that a proportion of counties show statistically insignificant trends for the variables being investigated, we still chose to show the nature of these trends. This is because of the fact that while statistically insignificant, these trends can still have potential 
implications on agricultural crop production by affecting yields, irrigation, risk of diseases/pests etc. and hence demand consideration. For the annual maximum air temperatures $\left(T_{\max }\right)$, almost all significant trends were increasing trends. The proportion of counties which showed increasing trends in $T_{\max }$ in the region is $71 \%$. Most of these significantly increasing trends were observed in the counties of Texas, along with a few counties in Colorado. Most of the region shows increasing trends, although they are insignificant. There were some areas that showed insignificant decreasing trends, which included Southeast North Dakota, Eastern South Dakota, Western Iowa, Central Nebraska, Eastern Kansas, and Central Oklahoma. The regional average increasing and decreasing trends in annual $\mathrm{T}_{\max }$ are $0.15^{\circ} \mathrm{C}$ decade $^{-1}$ and $0.08^{\circ} \mathrm{C}$ decade $^{-1}$, respectively.

The trends in growing-season $\mathrm{T}_{\max }$ show an interesting behavior across the region as well. The proportion of the counties which show positive and negative trends in growing-season $\mathrm{T}_{\max }$ are $48 \%$ and $52 \%$, respectively. The regional average increasing and decreasing trends in growing-season $\mathrm{T}_{\max }$ are $0.18^{\circ} \mathrm{C}$ decade $^{-1}$ and $0.21^{\circ} \mathrm{C}$ decade $^{-1}$, respectively. Figure 2 (b) shows that primarily the Northern, Eastern and Central parts of the region show decreasing trends, where several counties in Eastern North Dakota and South Dakota show significantly decreasing trends. On the contrary, the Western and Southern parts of the region show an increase in $\mathrm{T}_{\max }$. Similar to annual $\mathrm{T}_{\max }$, several counties in Texas show significantly increasing trends for growing-season $\mathrm{T}_{\max }$ along with some counties in Colorado. On the other hand, unlike the more dominant Northern positive trends in annual $\mathrm{T}_{\max }$, the growing-season mean maximum air temperatures show negative trends in the Northern region, with Eastern parts of North Dakota and South Dakota showing significantly negative trends. These observations of differences in trends between annual and growing-season mean maximum air temperatures show that an analyses focused on growing-season trends is crucial while observing climate change impacts on agricultural systems, rather than relying on annual trends. The study focusses on growing-season trends because of their potential implications on agricultural production systems in the region. The decreasing trends in growing-season $\mathrm{T}_{\max }$ might be due to cooling effect of irrigation, especially in counties with large 
acreages of irrigated summer crops such as those in South-Central Nebraska. This is because soil moisture affects surface albedo and evaporation and has been shown to influence regional temperature (Dai et al. 1999). However, the quantitative relationships between the irrigation expansion and temperature trends need to be investigated in the region, as a follow-up study by the authors. For example, Lobell and Bonfils (2008) observed that irrigated sites in California showed significantly negative trends in $\mathrm{T}_{\max }$ during June- August, owing to irrigation expansion in the region.

The trends for the growing-season months were very similar to the growing-season average trends explained above, with the counties in Northern and Eastern regions showing decreasing trends and the Southern and Western regions showing increasing trends. Significant increasing trends in many counties for November, January and March were observed. Likewise, counties in North Dakota and South Dakota show significant decreasing trends for May, June and October. The nature and significance of county-specific trends are shown in Figure 3 for each month of the year. There is a considerable variability in the nature of these trends for every month. It is an extremely arduous task to explain the variability that occurs for the trends observed in each county and state. The maps developed are somewhat self-explanatory in terms of describing the trends that were obtained in each month and can be used to extract invaluable information in this regard. Nevertheless, the trends for a single county on annual, growing-season and monthly scale can be explained in detail as an example; and for this purpose, Clay County in Nebraska was chosen as the region of interest. For Clay County, it was observed that the trends in $\mathrm{T}_{\max }$ were negative for most months, except January, March, November and December. Also, annual $\mathrm{T}_{\max }$ trend was positive, while the growing-season $\mathrm{T}_{\max }$ trend was negative. Out of all of the monthly trends, only the positive trend for November was statistically significant. Detailed information for the observed $\mathrm{T}_{\max }$ trends in Clay County, Nebraska is listed in Table 1.

\section{Minimum air temperature}

Trends in $T_{\min }$ (both annual and growing-season) are shown in Figure 4. Maps show that $\mathrm{T}_{\min }$ had highly dominant positive trends in almost all counties with substantial number of counties showing 
significant trends. About $90 \%$ of the counties in the region show positive trends. The regional average positive and negative trends in annual $\mathrm{T}_{\min }$ were $0.2^{\circ} \mathrm{C}$ decade ${ }^{-1}$ and $0.07^{\circ} \mathrm{C}$ decade ${ }^{-1}$ respectively. Moreover, the proportion of counties showing significant positive trends was roughly the same (90\%) for growing-season $\mathrm{T}_{\min }$ as the annual time scale. The regional average positive and negative trends in growing-season $\mathrm{T}_{\min }$ were found to be $0.19^{\circ} \mathrm{C}$ decade $^{-1}$ and $0.06^{\circ} \mathrm{C}$ decade $^{-1}$ respectively. Detailed maps for monthly trends in $\mathrm{T}_{\min }$ are shown in Figure 5. When investigating the monthly $\mathrm{T}_{\min }$ trends, it was found that all significant trends are increasing trends and only significant decreasing trends observed in some counties in Oklahoma for March, April, September, October, November and December. Most of the significant increasing trends were observed in the growing-season months. This strengthens our observations from the annual and growing-season maps that increasing $\mathrm{T}_{\min }$ trends are dominant in the region. Observing the trend statistics for the Clay County, Nebraska, monthly $\mathrm{T}_{\min }$ trends are positive for all of the months, except February, April and May. Similarly, annual and growing-season $\mathrm{T}_{\min }$ trends also had increasing trends for the county. No trends, whether annual, growing-season or monthly, were statistically significant. Detailed information for the observed $\mathrm{T}_{\min }$ trends in Clay County, Nebraska is listed in Table 1.

\section{Average air temperature}

The trends in annual and growing-season $\mathrm{T}_{\mathrm{avg}}$ are shown in Figure 6. Since the average air temperatures are derived from maximum and minimum air temperatures, it is expected that the trends in $\mathrm{T}_{\max }$ and $\mathrm{T}_{\min }$ would be inherited in $\mathrm{T}_{\mathrm{avg}}$. As discussed before, the trends in both annual and growingseason $\mathrm{T}_{\min }$ were positive, but $\mathrm{T}_{\max }$ had differential trends in the region. This resulted in increasing trends in annual $\mathrm{T}_{\text {avg }}$ in the counties where annual $\mathrm{T}_{\max }$ was increasing, since the annual $\mathrm{T}_{\min }$ had uniform increasing trends in the area. Some examples of these areas are Texas, Colorado and Wyoming. Also, we observed earlier annual $\mathrm{T}_{\max }$ had decreasing trends in certain counties in Northern, Central and Eastern states, and growing-season $\mathrm{T}_{\max }$ had very uniform decreasing trends in these parts. As a result, similar decreasing trends were found in $\mathrm{T}_{\mathrm{avg}}$, although some weaker $\mathrm{T}_{\max }$ decreasing trends were converted to 
positive $T_{\text {avg }}$ trends because of significant $T_{\min }$ trends. The proportion of counties which had positive trends in annual and growing-season $\mathrm{T}_{\text {avg }}$ are $85 \%$ and $62 \%$, respectively. The regional average positive and negative trends in annual $\mathrm{T}_{\text {avg }}$ are $0.16^{\circ} \mathrm{C}_{\text {decade }}{ }^{-1}$ and $0.06^{\circ} \mathrm{C}$ decade $^{-1}$, respectively. Similarly, the region averages for the positive and negative trends in growing-season $\mathrm{T}_{\text {avg }}$ are $0.17^{\circ} \mathrm{C}$ decade ${ }^{-1}$ and $0.09^{\circ} \mathrm{C}$ decade ${ }^{-1}$, respectively.

The maps showing monthly trends for the average air temperature are shown in Figure 7. Trends observed in Clay County, Nebraska were of similar nature as that of $\mathrm{T}_{\max }$, with the annual $\mathrm{T}_{\text {avg }}$ showing positive trends and growing-season $\mathrm{T}_{\mathrm{avg}}$ showing negative trends. Also, January, March, November and December showed positive $\mathrm{T}_{\text {avg }}$ trends, which were the same months when $\mathrm{T}_{\max }$ displayed positive trends. The trends observed in Clay county were not statistically significant. Detailed information for the observed $\mathrm{T}_{\text {avg }}$ trends in Clay County, Nebraska are listed in Table 1.

\section{Daily temperature range}

Trends in annual, growing-season and monthly daily air temperature range (DTR) on county basis have been computed for the period 1968-2013 using non-parametric tests (Figure 8). Annual DTR trends are negative for the majority of the region. The proportion of counties which showed negative annual DTR trends was 69\%. These negative trends were found for all counties in North Dakota, South Dakota and Wyoming. In Nebraska, except some counties in Southeast and East Central regions, all counties showed negative trends. In Iowa, majority of the counties showed negative trends, with the exception of some counties in Southwest and Southeast regions. Western Colorado showed negative trends, while Eastern Colorado showed positive trends. Similarly, Western Kansas had predominance of positive trends, whereas Eastern Kansas had negative trends. In Oklahoma, counties in the Central part of the state show positive trends. In Texas, counties in the High Plains, Trans Pecos, North Central and South Central regions showed positive trends. The negative trends found in some counties of North Dakota, South Dakota, Wyoming, Colorado, Oklahoma and Texas were statistically significant (shown in green color in Figure 8). On the other hand, there were some statistically significant $(P<0.05)$ positive trends in 
Colorado. The regional average positive and negative annual DTR trends were $0.08^{\circ} \mathrm{C}$ decade ${ }^{-1}$ and $0.14^{\circ} \mathrm{C}$ decade ${ }^{-1}$, respectively.

The negative trends in growing-season DTR are more dominant in the region than that in annual DTR. The proportion of the counties that showed negative trends in growing-season DTR is $80 \%$, which is $11 \%$ more than what was found for annual DTR. Figure 8 (b) shows the nature and significance of growing-season DTR trends over the study region. North Dakota, South Dakota, Iowa, Nebraska and Wyoming showed dominant negative trends, with most of them being statistically significant $(P<0.05)$. The distribution of positive and negative trends in the rest of the states is similar to that of annual DTR. The regional average positive and negative growing-season DTR trends were $0.09^{\circ} \mathrm{C}$ decade $^{-1}$ and $0.22^{\circ} \mathrm{C}$ decade $^{-1}$, respectively.

Monthly trends in DTR were calculated to better understand the changes that occur in the nature of trends and the regions in which they occur for every month of the year. Figure 9 shows the pattern and significance of the trends for each month. The Clay County, Nebraska, was randomly selected and investigated for detailed trends. It was found that the trends in monthly DTR are positive for January, March, November and December, while they are negative for the rest of the months. Also, the negative trends for June and July are statistically significant. Detailed information for the observed $\mathrm{T}_{\text {avg }}$ trends in Clay County, Nebraska is listed in Table 1. It is noteworthy that our maps [Figure 9 (e)-9 (i)] show that during the agricultural growing-season, there are highly dominant DTR decreases in the region, as compared to other months. Skaggs and Irmak (2012) studied changes in monthly and annual DTR at five locations across Nebraska during a 115-year period and concluded that three of the locations (Alliance, Culbertson and Fremont) had year-round decreases in DTR, while the other two locations (Hastings and Central City) experienced decreases in DTR primarily during the growing-season. Our analyses support these findings and extend this study to 834 counties across the region. Studies carried out over other parts of the globe reveal variable trends in DTR. For example, Makowski et al. (2008) found that DTR behavior in Europe over 1950 to 2005 changed from a decrease to an increase in the 1970s in Western 
Europe and in the 1980s in Eastern Europe. Sen Roy and Balling (2005) detected significant increases in both maximum and minimum temperatures for India, but insignificant trends in DTR over 1931- 2002. Christy et al. (2009) reported that for East Africa there has been a consistent narrowing of DTR in recent decades. Zhou and Ren (2012) reported a significant negative trend in DTR over mainland China of $0.15^{\circ} \mathrm{C}$ per decade during $1961-2008$. In our study, decrease in DTR across the region, which is the major observation drawn from our analysis, may be due to an increase in atmospheric moisture and decrease in incoming shortwave radiation. One of the likely explanations for the decreases found in growing-season DTR magnitudes is the significant irrigation expansion in the region.

\section{TRENDS IN PRECIPITATION}

Annual and growing-season precipitation trends for the period of 1968-2013 in the Great Plains region were calculated and their nature and statistical significance are shown in Figure 10. For the annual precipitation, $61 \%$ of the counties in the region showed increasing trends and the rest (39\%) showed decreasing trends. As shown in Figure 10 (a), all the counties in North Dakota and South Dakota showed positive trends. In Nebraska, except the East Central and Southeast region which showed negative trends, all other counties showed positive trends. Similarly, in Iowa, all counties showed positive trends, although there are some counties in Southwest, South Central, Southeast, Central and East Central region, which showed negative trends. In Kansas, North Central, West Central, Central and South central regions showed positive trends, while the rest of the state shows negative trends. In Wyoming, the counties along the border of South Dakota, Nebraska and Colorado showed positive trends, and the rest of the state was dominated by negative trends. Southwest and Central Colorado comprise of some counties which show negative trends, with the remainder of the state showing positive trends. Eastern Oklahoma showed negative trends, while the Western Oklahoma showed positive trends. Finally, decreasing trends were found for counties in Southern Texas, while the Northern Texas showed positive trends for the most part.

Of the increasing trends, the ones in the Western counties of North Dakota and South Dakota were statistically significant. Similarly, the Western and Southern counties in Texas showed statistically 
significant decreasing trends. The average magnitudes of the annual increasing and decreasing trends observed in the region were $1.45 \mathrm{~mm} \mathrm{yr}^{-1}$ and $1.35 \mathrm{~mm} \mathrm{yr}^{-1}$, respectively. It should be noted that these trend magnitudes are low because of regional averaging and that higher magnitudes exist for counties with significant positive and negative trends.

The growing-season precipitation trends [Figure 10 (b)] were also investigated for both their nature and significance for agricultural practices. About $57 \%$ of the counties in the region had positive trends and almost all the counties in the state of Texas showed negative trends, out of which the counties in the Trans Pecos, South central, East Texas were significant. Nebraska also had dominant increasing trends in growing-season precipitation. The magnitudes of growing-season increasing and decreasing trends were calculated as $1.12 \mathrm{~mm} \mathrm{yr}^{-1}$ and $1.16 \mathrm{~mm} \mathrm{yr}^{-1}$, respectively on a region average basis.

Trends in monthly precipitation were quantified and are shown in Figure 11 using maps for each month of the year. Observing the monthly trends, information can be gathered about the county scale trends in precipitation for any month. As an example, trends observed in Clay County, Nebraska, are listed in Table 1. Trends are positive for February, June, August and October, while negative trends have been found during the rest of the year. However, the only significant decreases in monthly precipitation were in March. The trend in growing-season precipitation was positive, while the annual precipitation was negative. Irmak et al. (2012) calculated trends in annual precipitation and several other climate variables at the Platte River Basin in Central Nebraska, USA, and concluded that the annual precipitation increased significantly during a 116-year period. In accordance, our results for the Merrick County, Nebraska (Platte River Basin) show that the annual precipitation increased during the study period at a rate of 3.9 mm decade ${ }^{-1}$ (statistically insignificant).

\section{TRENDS IN GRASS-REFERENCE ET}

Trends in annual and growing-season grass reference ET $\left(\mathrm{ET}_{\mathrm{o}}\right)$ were computed for each county in the study region and the nature and statistical significance of the observed trends are shown in Figure 12. The annual $\mathrm{ET}_{\mathrm{o}}$ has decreased over most of the region (Figure 12a). Specifically, $62 \%$ of the counties in 
the region showed decreasing trends and $38 \%$ of the counties had increasing trends. The counties showing decreasing trends are mostly in Iowa, North Dakota, South Dakota, Nebraska, Kansas, Oklahoma and Texas. Out of all counties that show decreasing trends, the ones in Eastern North Dakota and South Dakota show significant trends. However, increasing trends are observed in the Western states of Wyoming and Colorado. Also, High Plains, Trans Pecos, Low Rolling Plains, North central, East Texas, Upper Coast, Lower Valley, Southern and Edwards Plateau regions in Texas showed increasing trends. In Oklahoma, panhandle, Central, East Central, South Central regions had increasing trends. In Kansas, Southwest, West central, Central, North Central regions show increasing trends. In addition, Panhandle region in Nebraska; Northwest, Southwest and Black Hills region in South Dakota and Southwest region in North Dakota show increasing trends in $\mathrm{ET}_{\mathrm{o}}$. Out of all the aforementioned regions showing increasing trends, only the ones in Texas were statistically significant.

The growing-season $\mathrm{ET}_{\mathrm{o}}$ trends are represented in Figure 12 (b). About $72 \%$ of the counties showed negative $\mathrm{ET}_{\mathrm{o}}$ trends, which is higher than the proportion of negative trends observed in annual $\mathrm{ET}_{\mathrm{o}}$. Interestingly, all the counties in North Dakota, South Dakota, Iowa and Nebraska showed negative trends. The only increasing growing-season $\mathrm{ET}_{\mathrm{o}}$ trends observed in the region were those in Texas, Colorado and Wyoming and Southwest Kansas. However, unlike annual $\mathrm{ET}_{\mathrm{o}}$, the increasing trends in growing-season $\mathrm{ET}_{\mathrm{o}}$ observed in High Plains region of Texas were not significant. The magnitudes of the trends were also computed, although they are not represented on the maps. For the annual $\mathrm{ET}_{\mathrm{o}}$, the region average increasing trend was $0.58 \mathrm{~mm} \mathrm{yr}^{-1}$, whereas the region average decreasing trend was $0.79{\mathrm{~mm} \mathrm{yr}^{-}}^{-}$

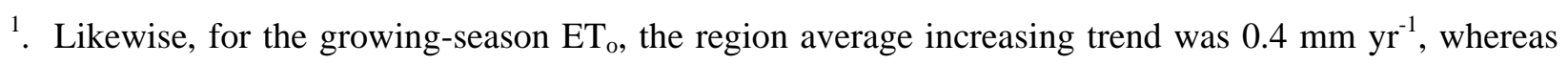
the region average decreasing trend was $0.76 \mathrm{~mm} \mathrm{yr}^{-1}$. The primary reason for negative trends in $\mathrm{ET}_{\mathrm{o}}$ is the negative trend in the term in the Hargreaves-Samani equation which represents temperature difference $\left.\left(\mathrm{T}_{\max }-\mathrm{T}_{\min }\right)^{1 / 2}\right)$. The dominant negative trends in this variable (DTR) across the region have been discussed earlier in this article. This term implicitly accounts for and is linearly related to relative humidity (Hargreaves and Samani, 1982), or vapor pressure deficit. Irmak et al. (2012) observed that 
change in $\mathrm{ET}_{\mathrm{o}}$ in Central Nebraska was highly correlated $\left(\mathrm{r}^{2}=0.84\right)$ to VPD and net radiation $\left(\mathrm{r}^{2}=0.52\right)$. The temperature-based equation used to compute $\mathrm{ET}_{\mathrm{o}}$ in this study does not account explicitly for other factors that can dictate trends in $\mathrm{ET}_{\mathrm{o}}$ and hence limit the explanation of change in $\mathrm{ET}_{\mathrm{o}}$ to change in temperature difference term.

Temporal trends for $\mathrm{ET}_{\mathrm{o}}$ were also investigated on a monthly basis (Figures 13). There is a considerable variability in the nature of these trends for monthly time step. In Clay County, Nebraska, randomly selected example region, monthly $\mathrm{ET}_{\mathrm{o}}$ trends were found to be positive for January, March, November and December, while they were negative for the rest of the months. Also, negative trends were observed for both annual and growing-season $\mathrm{ET}_{\mathrm{o}}$. However, none of the trends are statistically significant. The magnitudes of monthly, growing-season and annual $\mathrm{ET}_{\mathrm{o}}$ trends computed for Clay County are listed in Table 1. Irmak et al. (2012) also found negative trends for annual $\mathrm{ET}_{\mathrm{o}}$ at Central Platte River Basin, Nebraska, during the period from 1893 to 2008. This site being investigated is located in Merrick County and our study reports that negative annual $\mathrm{ET}_{\mathrm{o}}$ trends are observed for this county. Mutiibwa and Irmak (2013) sampled six locations in the High Plains regions in order to investigate the trends in daily $\mathrm{ET}_{\mathrm{o}}$ during the period from 1981 to 2008. They reported that six, two, and three out of six locations showed negative trends in daily June ET, July ET $_{\mathrm{o}}$, and August ET , $_{\mathrm{o}}$, respectively.

\section{TRENDS IN ARIDITY INDEX}

Trends in AI in the region during the period from 1968 to 2013 were computed in similar fashion as air temperatures, DTR, precipitation and $\mathrm{ET}_{\mathrm{o}}$ and the trends were tested for statistical significance. The nature and significance of the trends in annual and growing-season AI are represented in Figure 14. The majority of the counties showed increasing trends in annual AI, with $66 \%$ of the counties showing positive trends. The increasing trends were largely dominant in the Northern, Central and Eastern states. Specifically, all the counties in North Dakota, except the ones in Southwest and West central regions, showed increasing trends. Counties in South Dakota showed positive trends without any exceptions. Nebraska was also dominated by counties which showed positive trends, except East central and South 
east regions. Iowa, with the exception of Central and East central regions, showed positive trends. Kansas had several counties scattered throughout the state which showed negative trends. Counties in Western and Central Wyoming showed negative trends, which surpassed the number of positive trends in the state. Majority of the counties in Colorado showed positive trends, except some counties in Colorado Drainage Basin. In Oklahoma, except for the Eastern part of the state, all other counties showed positive trends. Lastly, Texas was dominated by positive trends in the Northern region, while negative trends prevailed in the remainder of the state. The significantly positive trends, however, were only found primarily in North and South Dakota. Also, the significantly negative trends were observed in Texas. The regional average magnitudes of the positive and negative trends in annual AI were 0.01 decade $^{-1}$ and -0.01 decade $^{-1}$, respectively.

The trends in growing-season AI were similar to the annual trends with $63 \%$ of the counties in the region showing positive trends. North and South Dakota, Nebraska, Iowa, Kansas and Oklahoma were predominantly occupied by counties which showed positive trends. Interestingly, majority of the state of North Dakota had significantly positive trends, in addition to several counties in South Dakota. The proportion and geography of the growing-season AI trends in Wyoming and Colorado were very similar to those of annual AI. Another striking observation was that Texas showed negative trends throughout, with a considerable number of counties in South central and East Texas showing statistically significant negative trends. The region average magnitudes of the positive and negative trends in growing-season AI were 0.02 decade $^{-1}$ and -0.02 decade $^{-1}$, respectively.

As with other variables, trends in AI were investigated on a monthly basis (Figure 15). The extent of information associated with individual maps does not enable us to discuss the individual county trends for each month, although conclusions about the same can be derived from observing the maps. We limit our analysis to the trends observed in Clay County, Nebraska, and report the results quantitatively in Table 1. The trends in monthly AI were positive for February, April and June and negative for all other months. All of the monthly trends were insignificant, except the increasing trend in June, which was 
statistically significant. Also, the growing-season AI at Clay Center had an increasing trend, while a negative trend was observed for the annual AI.

\section{DISCUSSION}

The analyses of spatial patterns of similar temporal trends in the region and grouping of regions with similar trends are crucial to synthesize and interpret the climate change observations for the region. Equally important is to study the patterns of each of the variables together in regions which show consistent trends across the Great Plains. For all the variables studied, the Eastern North Dakota and South Dakota show significant trends during the growing season. This region is characterized by decreasing trends in $\mathrm{T}_{\max }$, increasing trends in $\mathrm{T}_{\min }$, resulting in decreasing trends in DTR for the entire two states. Growing-season precipitation shows a positive trend, while $\mathrm{ET}_{\mathrm{o}}$ decreased during the period. Decreases in DTR in these regions might be due to an increase in atmospheric moisture, cloudiness and decrease in incoming shortwave radiation, which is also coherent to positive trends in precipitation (Skaggs and Irmak, 2012). These differential trends in $\mathrm{P}$ and $\mathrm{ET}_{\mathrm{o}}$ imply increasing trends in aridity index in the Eastern North Dakota and South Dakota. Another group of counties which show consistent trends for all the variables is the Southeast Texas. This region, unlike the northern counties, show increases in both $\mathrm{T}_{\max }$ and $\mathrm{T}_{\min }$, resulting in increase in DTR over the study period. Precipitation, on the other hand, shows decreasing trends, while $\mathrm{ET}_{\mathrm{o}}$ shows increasing trends, driving trends in aridity index in a negative direction. Thus, the trends in all the variables are contrasting or opposite in nature for the two regions in the Northern and Southern Great Plains, as discussed above, except $\mathrm{T}_{\min }$, for which dominant increasing trends were prevalent in the study region. Thus, the nature and magnitudes of temporal trends vary substantially throughout the region and it is hence crucial to investigate and analyze these trends at smaller scales rather than aggregating the trends on larger scales. Apart from these, several other regions exist with mixed or inconsistent trends in some variables, which are discussed in detail in the Results section. Some of these regions are parts of Colorado, Wyoming, Iowa, Oklahoma, Texas (significant 
trends in $\mathrm{T}_{\max }, \mathrm{T}_{\min }$, DTR), Central Nebraska (significant trends in DTR), Western counties in Texas (significant trends in precipitation, $\mathrm{ET}_{0}$ and $\mathrm{AI}$ ).

The observed trends, in either direction, have the potential to impact food production in the region, which consequently have ramifications for the region as an agricultural food bowl. According to Skaggs and Irmak (2012), the period of grain development in cereals is primarily governed by air temperature, decreased $\mathrm{T}_{\max }$ during this period can extend the maturity of the crops, which results in improved crop yields. Therefore, decreases in $\mathrm{T}_{\max }$ imply positive impacts on crop physiological development, biomass accumulation, and grain yield, especially during silking and grain-filling stages for maize and during pod formation and pod-filling stages for soybean, which occur around the July month in our study region. Additionally, decreases in $\mathrm{T}_{\max }$ can reduce evaporative losses and prevent crop water stress, resulting in lower crop water requirements. Figure 2(b) and 3(g) show that in majority of the region, decreasing $\mathrm{T}_{\max }$ is observed during the growing season and the month of July, respectively, which can potentially mean increased yields or lower crop water requirements in these regions. In contrast, if $\mathrm{T}_{\max }$ is persistently high for longer periods, reduction in number of kernels per ear in maize and number of grains per pod in soybean can occur, resulting in reduced yields. More severe impacts are caused due to higher temperatures around anthesis. Increased $\mathrm{T}_{\max }$ during the period from the initiation of the meiosis in the male generative tissue to the completion of anthesis can affect the pollination process by reducing the grain set for cereals (Smika and Shawcroft 1980). Moreover, successful production and transfer of viable pollen grains to the stigma, germination of the pollen grains and growth of the pollen tubes below the style, and fertilization and development of the zygote, are all crucial for maximum productivity and are sensitive to temperature (Ferris et al. 1998). Also, during higher $\mathrm{T}_{\max }$ conditions, greater atmospheric evaporative demand due to high vapor pressure deficit results in plant water stress, which also stresses the importance of investigating trends in reference evapotranspiration. In such cases, plant stomata may not be able to maintain the high rate of plant water uptake demand. As a consequence, plants may close their stoma, which causes reduction in the transpiration rate and dry matter accumulation. Increases in $\mathrm{T}_{\min }$ 
may have significant implications in crop productivity by accelerating plant respiration, causing increase in dry matter consumption by the plants at night, and result in reduction in crop yields. A response of crop yields to DTR changes is expected because many plant processes are nonlinearly related to temperature, so that the effects of increased temperature may be different during day and night. For example, increased DTR for a given $T_{\text {avg }}$ may cause reduction in yields because the accompanying increase in $T_{\max }$ causes increased water stress or photosynthesis rate reduction (Dhakhwa and Campbell, 1998). In regions where freezing temperatures can result in crop injury or death, reductions in $\mathrm{T}_{\min }$ associated with increased DTR can be harmful (Rosenzweig and Tubiello, 1996; Tubiello et al., 2002). Alternatively, increased DTR may benefit yields in cases where development or grain filling rates are more sensitive to $T_{\min }$ than $T_{\max }$ (Wilkens and Singh, 2001), with crops able to grow longer and produce more grain with lower nighttime temperatures. Increases in DTR can positively impact crops such as fruit and nut trees, which benefit from increased chilling hour accumulation (Lobell et al., 2006). Increased DTR is usually associated with increased solar radiation (Bristow and Campbell, 1984), which can result in higher crop yields, primarily for well fertilized and irrigated fields (Monteith, 1972; Fischer, 1985). The crop yields in Southwest Texas region which experiences significantly increasing DTR trends during the growing season may either be improved or reduced, depending on the processes that get affected. Precipitation influences crop water use by governing the moisture availability in the soil, which further affects the water uptake and loss by the plants through the process of transpiration. This can affect dry matter accumulation, which is directly related to transpiration. Increases in precipitation amounts (found in North Dakota and South Dakota) favors the soil moisture conditions and hence crop yields, whereas decreases in precipitation (found in Western and Southwest Texas) can result in drought conditions and yields can suffer, especially in rainfed fields. Aridity index quantitatively indicates the degree of water vapor deficiency to meet the evaporation demand at a given geographical location. For example, Figure 14 (b) implies that Eastern and Central North Dakota and Eastern South Dakota, during the growing seasons of the period 1968-2013 became less humid and an increase in their ability to meet the evaporation demand was observed, whereas the opposite was true for the Southwest Texas region. The agricultural implications caused by these 
climate/ hydrologic variables, as discussed above, can be evaluated on county-scale, both qualitatively and quantitatively, using the trends shown in the developed maps and the corresponding datasets.

\section{CONCLUSIONS}

This study used datasets that were developed in the Part I of this study [Kukal and Irmak (2016); this issue] to extract county-level statistics for each year in the period from 1968 to 2013, which included monthly, growing-season and annual magnitudes of air temperatures, DTR, precipitation, ET $\mathrm{o}_{\mathrm{o}}$ and AI. These variables were explored for temporal changes/trends that occurred during the 46-year period for each county using non-parametric tests. Maps indicating the nature and statistical significance for county trends were developed for all the variables to analyze the areas which showed increasing/decreasing tendencies in the region. The study results and conclusions are summarized as:

- The proportion of counties which showed increasing trends in $\mathrm{T}_{\max }$ in the region is $71 \%$. The regional average increasing and decreasing trends in annual $\mathrm{T}_{\max }$ are $0.15^{\circ} \mathrm{C}$ decade $^{-1}$ and $0.08^{\circ} \mathrm{C}$ decade $^{-1}$, respectively. The proportion of the counties which show positive and negative trends in growing-season $\mathrm{T}_{\max }$ are $48 \%$ and $52 \%$, respectively. The regional average increasing and decreasing trends in growing-season $\mathrm{T}_{\max }$ are $0.18^{\circ} \mathrm{C}$ decade $^{-1}$ and $0.21^{\circ} \mathrm{C}$ decade $^{-1}$, respectively. These observations of differences in trends between annual and growing-season mean maximum air temperatures show that an analyses focused on growing-season trends is crucial while observing climate change impacts on agricultural systems, rather than relying on annual trends. The regional average positive and negative trends in annual $\mathrm{T}_{\min }$ were $0.2^{\circ} \mathrm{C}$ decade $^{-1}$ and $0.07^{\circ} \mathrm{C}$ decade $^{-1}$ respectively.

- The regional average positive and negative trends in growing-season $\mathrm{T}_{\min }$ were found to be $0.19^{\circ} \mathrm{C}$ decade $^{-1}$ and $0.06^{\circ} \mathrm{C}$ decade $^{-1}$ respectively. Increasing $\mathrm{T}_{\min }$ trends are dominant in the region. The regional average positive and negative annual DTR trends were $0.08^{\circ} \mathrm{C}$ decade $^{-1}$ and $0.14^{\circ} \mathrm{C}$ decade $^{-1}$, respectively. The negative trends in growing-season DTR are more dominant in 
the region than that in annual DTR. The regional average positive and negative growing-season DTR trends were $0.09^{\circ} \mathrm{C}$ decade $^{-1}$ and $0.22^{\circ} \mathrm{C} \mathrm{decade}^{-1}$, respectively.

- For the annual precipitation, $61 \%$ of the counties in the region showed increasing trends and the rest (39\%) showed decreasing trends. The average magnitudes of the annual increasing and decreasing trends observed in the region were $1.45 \mathrm{~mm} \mathrm{yr}^{-1}$ and $1.35 \mathrm{~mm} \mathrm{yr}^{-1}$, respectively. The magnitudes of growing-season increasing and decreasing trends were calculated as $1.12 \mathrm{~mm} \mathrm{yr}^{-1}$ and $1.16 \mathrm{~mm} \mathrm{yr}^{-1}$, respectively on a region average basis.

- The annual $\mathrm{ET}_{\mathrm{o}}$ decreased over most of the region. Specifically, $62 \%$ of the counties in the region showed decreasing trends, as opposed to $38 \%$ counties having increasing trends. For the annual $\mathrm{ET}_{\mathrm{o}}$, the region average increasing trend was $0.58 \mathrm{~mm} \mathrm{yr}^{-1}$, whereas the region average

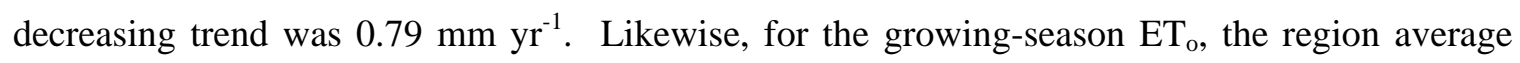
increasing trend was $0.4 \mathrm{~mm} \mathrm{yr}^{-1}$, whereas the region average decreasing trend was $0.76 \mathrm{~mm} \mathrm{yr}^{-1}$.

- The majority of the counties showed increasing trends in annual AI, with $66 \%$ of the counties showing positive trends. The regional average magnitudes of the positive and negative trends in annual AI were 0.01 decade $^{-1}$ and -0.01 decade $^{-1}$, respectively. The trends in growing-season AI were similar to the annual trends with $63 \%$ of the counties in the region showing positive trends. The region average magnitudes of the positive and negative trends in growing-season AI were 0.02 decade $^{-1}$ and -0.02 decade $^{-1}$, respectively.

The maps developed and data and information presented in this study can be used to analyze county-level trends in important climatic variables and indices in studies involving various disciplines and topics, including climate change, water resources, agriculture and natural resources response to climate change, etc. Studying the spatial distribution of temporal trends is crucially important due to the fact that the observed trends in various variables are uniform in neither magnitude nor nature. Moreover, the growing-season trends in various variables can aid to better understand the influence of trends in various 
variables on the agricultural and natural resources production systems, dynamics of hydrologic components and their interactions with climate variables under changing climatic conditions.

\section{ACKNOWLEDGEMENT}

This study is based upon the work that is supported by the National Institute of Food and Agriculture, U.S. Department of Agriculture, Hatch Project, under the Project Number NEB-21-167. This study was also supported by the grants from the Nebraska Environmental Trust (NET) under the project agreement \#13-146 and the Central Platte Natural Resources District (CPNRD) under the grant agreement \#38484. The projects Principal Investigator, Dr. Suat Irmak expresses his appreciation to USDA-NIFA, NET and CPNRD.

\section{REFERENCES}

Andreadis, K.M., Lettenmaier, D.P., 2006. Assimilating remotely sensed snow observations into a macroscale hydrology model. Adv.Water Resour. 29, 872-886.

Aziz, O.I.A., Burn, D.H., 2006. Trends and variability in the hydrological regime of the Mackenzie River Basin. Journal of hydrology. 319, 282-294.

Bakhsh, A., Kanwar, R.S., 2004. Using discriminant analysis and GIS to delineate subsurface drainage patterns. Trans.ASAE. 47, 689.

Böhm, R., Jones, P.D., Hiebl, J., Frank, D., Brunetti, M., Maugeri, M., 2010. The early instrumental warm-bias: a solution for long central European temperature series 1760-2007. Clim.Change. 101, 41-67.

Bristow, K.L., Campbell, G.S., 1984. On the relationship between incoming solar radiation and daily maximum and minimum temperature. Agric.For.Meteorol. 31, 159-166.

Burn, D.H., 2008. Climatic influences on streamflow timing in the headwaters of the Mackenzie River Basin. Journal of Hydrology. 352, 225-238. 
Burn, D.H., Hesch, N.M., 2007. Trends in evaporation for the Canadian Prairies. Journal of Hydrology. 336, 61-73.

Chattopadhyay, N., Hulme, M., 1997. Evaporation and potential evapotranspiration in India under conditions of recent and future climate change. Agric.For.Meteorol. 87, 55-73.

Christy, J.R., Norris, W.B., McNider, R.T., 2009. Surface temperature variations in East Africa and possible causes. J.Clim. 22, 3342-3356.

Dai, A., Trenberth, K. E. and Karl, T. R., 1999. Effects of clouds, soil moisture, precipitation, and water vapor on diurnal temperature range. J. Clim. 12, 2451-2473.

Deni, S.M., Suhaila, J., Zin, W.Z.W., Jemain, A.A., 2010. Spatial trends of dry spells over Peninsular Malaysia during monsoon seasons. Theoretical and applied climatology. 99, 357-371.

Dhakhwa, G.B., Campbell, C.L., 1998. Potential effects of differential day-night warming in global climate change on crop production. Clim.Change. 40, 647-667.

Falvey, M., Garreaud, R.D., 2009. Regional cooling in a warming world: Recent temperature trends in the southeast Pacific and along the west coast of subtropical South America (1979-2006). Journal of Geophysical Research: Atmospheres. 114.

Ferris, R., Ellis, R., Wheeler, T., Hadley, P., 1998. Effect of high temperature stress at anthesis on grain yield and biomass of field-grown crops of wheat. Annals of Botany. 82, 631-639.

Fischer, R., 1985. Number of kernels in wheat crops and the influence of solar radiation and temperature. The Journal of Agricultural Science. 105, 447-461.

Fu, Q., Feng, S., 2014. Responses of terrestrial aridity to global warming. Journal of Geophysical Research: Atmospheres. 119, 7863-7875. 
Gao, Y., Li, X., Leung, L.R., Chen, D., Xu, J., 2015. Aridity changes in the Tibetan Plateau in a warming climate. Environmental Research Letters. 10, 034013.

Hargreaves, G. H., \& Samani, Z. A., 1982. Estimating potential evapotranspiration. Journal of the Irrigation and Drainage Division. 108(3), 225-230.

Huntington, T.G., 2006. Evidence for intensification of the global water cycle: review and synthesis. Journal of Hydrology. 319, 83-95.

Intergovernmental Panel on Climate Change, 2007. Climate Change 2007 - Mitigation of Climate Change, Working Group III contribution to the Fourth Assessment Report of the IPCC, Cambridge, Cambridge University Press.

Intergovernmental Panel on Climate Change, 2013. Climate Change 2013: The Physical Science Basis. Contribution of Working Group I to the Fifth Assessment Report of the Intergovernmental Panel on Climate Change, Cambridge University Press, Cambridge, United Kingdom and New York, NY, USA.

Irmak, S., 2010. Nebraska water and energy flux measurement, modeling, and research network (NEBFLUX). Transactions of the ASABE. 53, 1097-1115.

Irmak, S., Kabenge, I., Skaggs, K.E., Mutiibwa, D., 2012. Trend and magnitude of changes in climate variables and reference evapotranspiration over 116-yr period in the Platte River Basin, central NebraskaUSA. Journal of Hydrology. 420, 228-244.

Jain, S.K., Keshri, R., Goswami, A., Sarkar, A., 2010. Application of meteorological and vegetation indices for evaluation of drought impact: a case study for Rajasthan, India. Nat.Hazards. 54, 643-656.

Jain, S.K., Kumar, V., 2012. Trend analysis of rainfall and temperature data for India. Current Science(Bangalore). 102, 37-49. 
Jhajharia, D., Shrivastava, S., Sarkar, D., Sarkar, S., 2009. Temporal characteristics of pan evaporation trends under the humid conditions of northeast India. Agric.For.Meteorol. 149, 763-770.

Jung, M., Reichstein, M., Ciais, P., Seneviratne, S.I., Sheffield, J., Goulden, M.L., et al., 2010. Recent decline in the global land evapotranspiration trend due to limited moisture supply. Nature. 467, 951-954.

Kahya, E., Kalayc1, S., 2004. Trend analysis of streamflow in Turkey. Journal of Hydrology. 289, 128144.

Karl, T.R., Knight, R.W., Gallo, K.P., Peterson, T.C., Jones, P.D., Kukla, G., et al., 1993. A new perspective on recent global warming: asymmetric trends of daily maximum and minimum temperature. Bull.Am.Meteorol.Soc. 74, 1007-1023.

Kendall, M.G., 1948. Rank correlation methods.

Kukal, M., Irmak, S., 2016. Long-Term Patterns of Air Temperatures, Daily Temperature Range, Precipitation, Grass-Reference Evapotranspiration and Aridity Index in The USA Great Plains: Part I. Spatial Trends. Journal of Hydrology.

Kulkarni, S., Bajwa, S., Rupe, J., Kirkpatrick, T., 2008. Spatial correlation of crop response to soybean cyst nematode (Heterodera glycines). Transactions of the ASABE. 51, 1451-1459.

Li, Q., Dong, W., Li, W., Gao, X., Jones, P., Kennedy, J., et al., 2010. Assessment of the uncertainties in temperature change in China during the last century. Chinese Science Bulletin. 55, 1974-1982.

Li, Q., Zhang, H., Chen, J., Li, W., Liu, X., Jones, P., 2009. A mainland China homogenized historical temperature dataset of 1951-2004. Bull.Am.Meteorol.Soc. 90, 1062.

Lins, H.F., Slack, J.R., 2005. Seasonal and regional characteristics of US streamflow trends in the United States from 1940 to 1999. Physical Geography. 26, 489-501. 
Liu, L., Hong, Y., Bednarczyk, C.N., Yong, B., Shafer, M.A., Riley, R., et al., 2012. Hydroclimatological drought analyses and projections using meteorological and hydrological drought indices: a case study in Blue River Basin, Oklahoma. Water Resour.Manage. 26, 2761-2779.

Liu, Q., Yang, Z., 2010. Quantitative estimation of the impact of climate change on actual evapotranspiration in the Yellow River Basin, China. Journal of hydrology. 395, 226-234.

Lobell, D.B., Bonfils, C., 2008. The effect of irrigation on regional temperatures: A spatial and temporal analysis of trends in California, 1934-2002. J.Clim. 21, 2063-2071.

Lobell, D.B., Field, C.B., Cahill, K.N., Bonfils, C., 2006. Impacts of future climate change on California perennial crop yields: Model projections with climate and crop uncertainties. Agric.For.Meteorol. 141, 208-218.

Makowski, K., Wild, M., Ohmura, A., 2008. Diurnal temperature range over Europe between 1950 and 2005. Atmospheric Chemistry and Physics. 8, 6483-6498.

Maliva, R., Missimer, T., 2012. Arid lands water evaluation and management, Springer Science \& Business Media.

Mann, H.B., 1945. Nonparametric tests against trend. Econometrica: Journal of the Econometric Society., 245-259.

Martinez, C.J., Maleski, J.J., Miller, M.F., 2012. Trends in precipitation and temperature in Florida, USA. Journal of hydrology. 452, 259-281.

McMahon, T., Peel, M., Lowe, L., Srikanthan, R., McVicar, T., 2013. Estimating actual, potential, reference crop and pan evaporation using standard meteorological data: a pragmatic synthesis. Hydrology and Earth System Sciences. 17, 1331-1363.

Middleton, N., Thomas, D., 1997. UNEP world atlas of desertification. Edward Arnold, London., 304. 
Mishra, V., Lettenmaier, D.P., 2011. Climatic trends in major US urban areas, 1950-2009. Geophys.Res.Lett. 38 .

Monteith, J., 1972. Solar radiation and productivity in tropical ecosystems. J.Appl.Ecol. 9, 747-766.

Moonen, A., Ercoli, L., Mariotti, M., Masoni, A., 2002. Climate change in Italy indicated by agrometeorological indices over 122 years. Agric.For.Meteorol. 111, 13-27.

Mutiibwa, D., Irmak, S., 2013. AVHRR-NDVI-based crop coefficients for analyzing long-term trends in evapotranspiration in relation to changing climate in the US High Plains. Water Resour.Res. 49, 231-244.

Peterson, T., 1995. Evaporation losing its strength. Nature. 377, 687-688.

Peterson, T. C., Willett, K. M., Thorne, P.W., 2011. Observed changes in surface atmospheric energy over land, Geophys.Res.Lett., 38, L16707

Rosenzweig, C., Tubiello, F.N., 1996. Effects of changes in minimum and maximum temperature on wheat yields in the central US A simulation study. Agric.For.Meteorol. 80, 215-230.

Roy, S.S., Balling, R.C., 2005. Analysis of trends in maximum and minimum temperature, diurnal temperature range, and cloud cover over India. Geophys.Res.Lett. 32.

Sahoo, D., Smith, P., 2009. Hydroclimatic trend detection in a rapidly urbanizing semi-arid and coastal river basin. Journal of Hydrology. 367, 217-227.

Schönwiese, C. Rapp., J., 1997: Climate Trend Atlas of Europe Based on Observations 1891-1990.

Schrier, G., Ulden, A.v., Van Oldenborgh, G., 2011. The construction of a Central Netherlands temperature. Climate of the Past. 7, 527-542.

Sen, P.K., 1968. Estimates of the regression coefficient based on Kendall's tau. Journal of the American Statistical Association. 63, 1379-1389. 
Sharma, V., Irmak, S., 2012. Mapping spatially interpolated precipitation, reference evapotranspiration, actual crop evapotranspiration, and net irrigation requirements in Nebraska: Part I. Precipitation and reference evapotranspiration. Transactions of the ASABE. 55, 907-921.

Skaggs, K.E., Irmak, S., 2012. Long-term trends in air temperature distribution and extremes, growing degree-days, and spring and fall frosts for climate impact assessments on agricultural practices in nebraska. Journal of Applied Meteorology and Climatology. 51, 2060-2073.

Smika, D., Shawcroft, R., 1980. Preliminary study using a wind tunnel to determine the effect of hot wind on a wheat crop. Field Crops Res. 3, 129-135.

Tang, G., Ding, Y., Wang, S., Ren, G., Liu, H., Zhang, L., 2010. Comparative analysis of China surface air temperature series for the past 100 years. Advances in Climate Change Research. 1, 11-19.

Tatli, H., Türkeş, M., 2011. Empirical orthogonal function analysis of the Palmer drought indices. Agric.For.Meteorol. 151, 981-991.

Tebakari, T., Yoshitani, J., Suvanpimol, C., 2005. Time-space trend analysis in pan evaporation over Kingdom of Thailand. J.Hydrol.Eng.

Tietäväinen, H., Tuomenvirta, H., Venäläinen, A., 2010. Annual and seasonal mean temperatures in Finland during the last 160 years based on gridded temperature data. Int.J.Climatol. 30, 2247-2256.

Trewin, B., 2013. A daily homogenized temperature data set for Australia. Int.J.Climatol. 33, 1510-1529.

Tubiello, F., Rosenzweig, C., Goldberg, R., Jagtap, S., Jones, J., 2002. Effects of climate change on US crop production: simulation results using two different GCM scenarios. Part I: Wheat, potato, maize, and citrus. Climate Research. 20, 259-270.

U.S. Census Bureau (2009). Retrieved from http://quickfacts.census.gov. 
Vasiliades, L., Loukas, A., Liberis, N., 2011. A water balance derived drought index for Pinios River Basin, Greece. Water Resour.Manage. 25, 1087-1101.

Vincent, L.A., Wang, X.L., Milewska, E.J., Wan, H., Yang, F., Swail, V., 2012. A second generation of homogenized Canadian monthly surface air temperature for climate trend analysis. Journal of Geophysical Research: Atmospheres. 117.

Wang, B., Bao, Q., Hoskins, B., Wu, G., Liu, Y., 2008. Tibetan Plateau warming and precipitation changes in East Asia. Geophys.Res.Lett. 35.

Wilkens, P and Singh, U., 2001. A code-level analysis for temperature effects in the 5 CERES models. In: J. White (Editor), Modeling temperature response in wheat 6 and maize. CIMMYT, El Batan, Mexico, pp. $1-7$

Winkler, P., 2009. Revision and necessary correction of the long-term temperature series of Hohenpeissenberg, 1781-2006. Theoretical and applied climatology. 98, 259-268.

Xu, C., Gong, L., Jiang, T., Chen, D., Singh, V., 2006. Analysis of spatial distribution and temporal trend of reference evapotranspiration and pan evaporation in Changjiang (Yangtze River) catchment. Journal of Hydrology. 327, 81-93.

$\mathrm{Xu}, \mathrm{C}$. , Singh, V., 2005. Evaluation of three complementary relationship evapotranspiration models by water balance approach to estimate actual regional evapotranspiration in different climatic regions. Journal of Hydrology. 308, 105-121.

Yuxiang, D., 2004. Sandy desertification status and its driving mechanism in North Tibet Plateau. Journal of Mountain Science. 1, 65-73.

Zhai, P., Sun, A., Ren, F., Liu, X., Gao, B., Zhang, Q., 1999. Changes of climate extremes in China,Weather and Climate Extremes, Springer, pp. 203-218. 
Zhang, X., Harvey, K.D., Hogg, W., Yuzyk, T.R., 2001. Trends in Canadian streamflow. Water Resour.Res. 37, 987-998.

Zhen, L., Zhong-Wei, Y., 2009. Homogenized daily mean/maximum/minimum temperature series for China from 1960-2008. Atmospheric and Oceanic Science Letters. 2, 237-243.

Zhongwei, Y., Chi, Y., 2000. Geographic Patterns of Extreme Climate Changes in China during 19511997 [J]. Climatic and Environmental Research. 3, 004.

Zhou, Y., Ren, G., 2012. Change in extreme temperature event frequency over mainland China, 19612008. Climate Research. 50, 125.

Ziegler, A.D., Maurer, E.P., Sheffield, J., Nijssen, B., Wood, E.F., Lettenmaier, D.P., 2005. Detection time for plausible changes in annual precipitation, evapotranspiration, and streamflow in three Mississippi River sub-basins. Clim.Change. 72, 17-36. 
Table 1. Trend statistics observed for Clay County, Nebraska during the period 1968-2013. Trends in bold indicate that the observed trend is statistically significant at $95 \%$ confidence level.

\begin{tabular}{|c|c|c|c|c|c|c|c|}
\hline \multirow[b]{2}{*}{ Months } & \multicolumn{7}{|c|}{ Trend (change $\mathrm{yr}^{-1}$ ) } \\
\hline & $\begin{array}{c}\text { Tmax } \\
\left({ }^{\circ} \mathbf{C ~ y r}^{-1}\right) \\
\end{array}$ & $\begin{array}{c}\text { Tminin } \\
\left({ }^{\circ} \mathbf{C ~ y r}^{-1}\right) \\
\end{array}$ & $\begin{array}{c}\text { Tavg } \\
\left({ }^{\circ} \mathbf{C ~ y r}^{-1}\right) \\
\end{array}$ & $\begin{array}{c}\text { DTR } \\
\left({ }^{\circ} \mathbf{C ~ y r}^{-1}\right) \\
\end{array}$ & $\begin{array}{c}\mathbf{P} \\
\left(\mathbf{m m ~} \mathbf{y r}^{-1}\right)\end{array}$ & $\begin{array}{c}\mathbf{E T}_{\mathbf{o}} \\
\left(\mathbf{m m ~ y r}^{-1}\right)\end{array}$ & $\begin{array}{c}\text { Aridity } \\
\left(\mathbf{y r}^{-1}\right)\end{array}$ \\
\hline January & 0.0763 & 0.0657 & 0.0687 & 0.0039 & -0.0060 & 0.1658 & -0.0026 \\
\hline February & -0.0024 & -0.0024 & -0.0002 & -0.0036 & 0.1521 & -0.0156 & 0.0045 \\
\hline March & 0.0335 & 0.0143 & 0.0247 & 0.0254 & -0.6828 & 0.1138 & -0.0022 \\
\hline April & -0.0111 & -0.0112 & -0.0114 & -0.0017 & -0.0158 & -0.0491 & 0.0001 \\
\hline May & -0.0060 & -0.0004 & -0.0045 & -0.0029 & -0.0420 & -0.0363 & -0.0009 \\
\hline June & -0.0353 & 0.0118 & -0.0128 & -0.0389 & 0.6573 & -0.3369 & 0.0032 \\
\hline July & -0.0352 & 0.0083 & -0.0133 & -0.0413 & -0.0583 & -0.3280 & -0.0012 \\
\hline August & -0.0287 & 0.0100 & -0.0079 & -0.0290 & 0.0179 & -0.2324 & -0.0006 \\
\hline September & -0.0013 & 0.0041 & -0.0012 & -0.0079 & -0.5480 & -0.0169 & -0.0017 \\
\hline October & -0.0222 & 0.0028 & -0.0025 & -0.0043 & 0.2853 & -0.1374 & -0.0020 \\
\hline November & 0.0607 & 0.0210 & 0.0379 & 0.0456 & -0.4897 & 0.1719 & -0.0064 \\
\hline December & 0.0165 & 0.0127 & 0.0195 & 0.0140 & -0.0851 & 0.0334 & -0.0044 \\
\hline $\begin{array}{c}\text { Growing- } \\
\text { season }\end{array}$ & -0.0205 & 0.0054 & -0.0066 & -0.0235 & 0.2876 & -0.9481 & 0.0012 \\
\hline Annual & 0.0038 & 0.0116 & 0.0081 & -0.0072 & -0.8472 & -0.6282 & -0.0004 \\
\hline
\end{tabular}




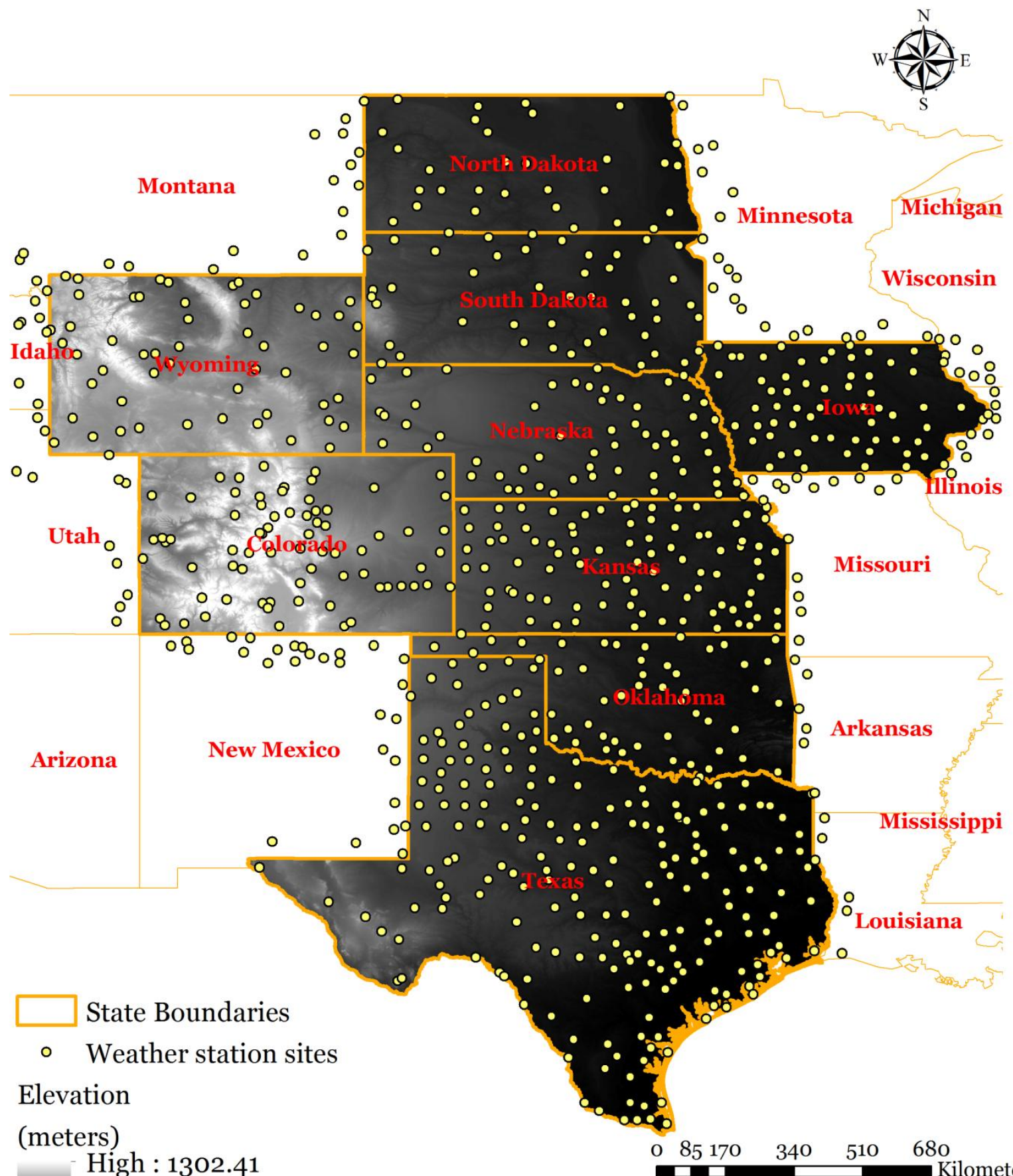

High : 1302.41

Kilometers

Low : 0

Figure 1. Mean sea level elevation across the study area and the geographical locations of the weather stations selected for the interpolation procedure. 
a)

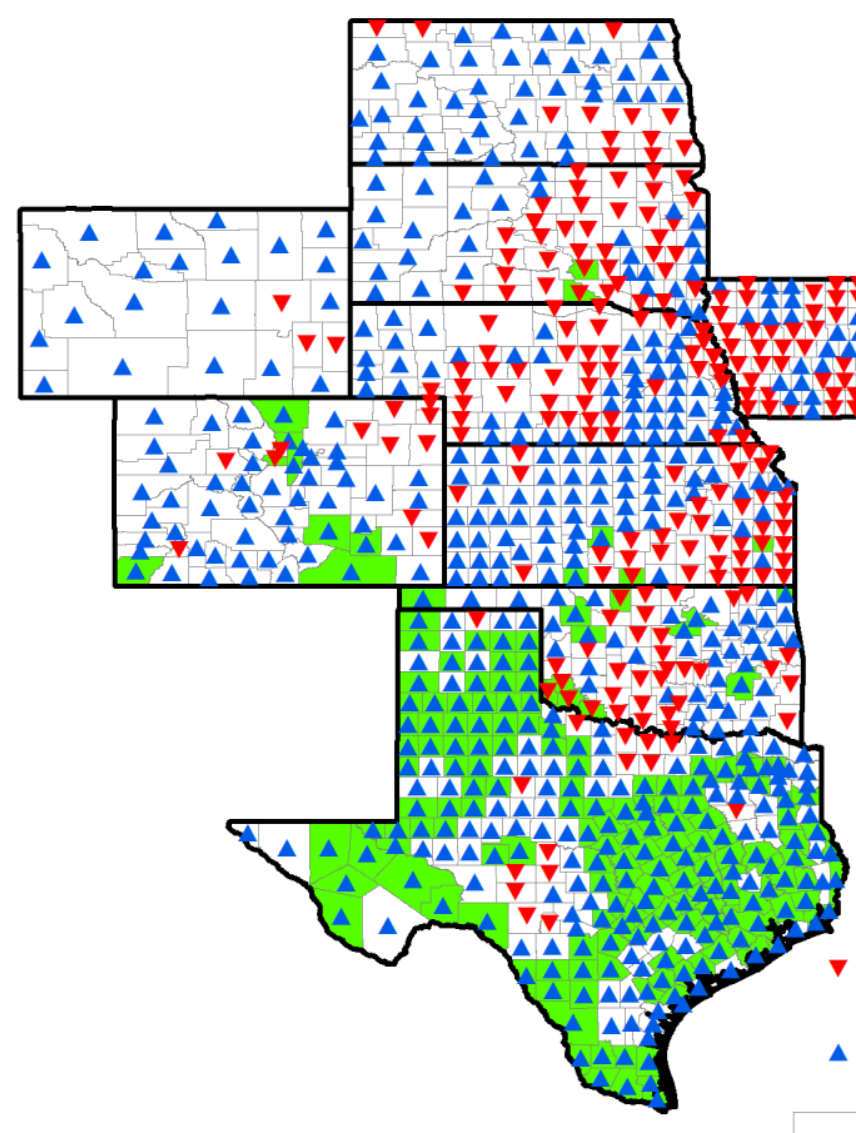

b)

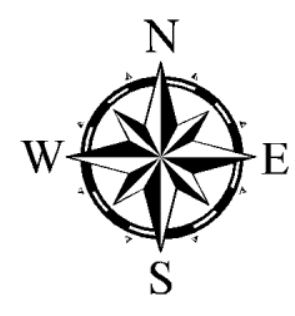

Decreasing trend

Increasing trend Non-significant

Significant

O $180360 \quad 720 \quad 1,080 \quad 1,440$

Kilometers

Figure 2. Spatial distribution and statistical significance of county-based trends in $\mathrm{T}_{\max }$ on a) Annual b) Growing-season basis. 
a)

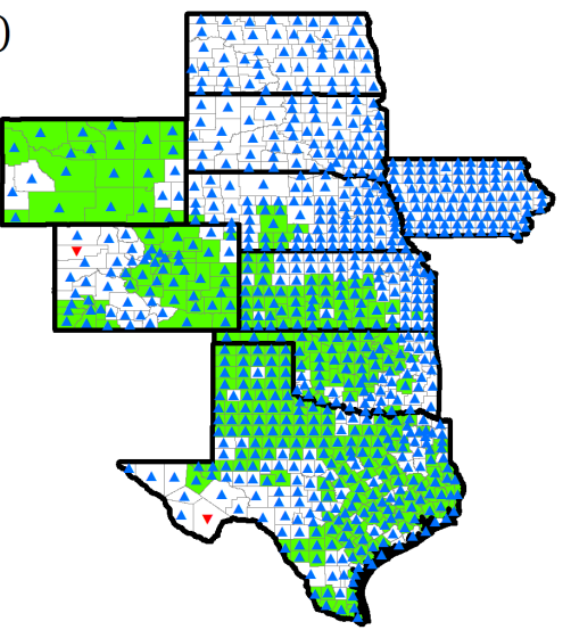

c)

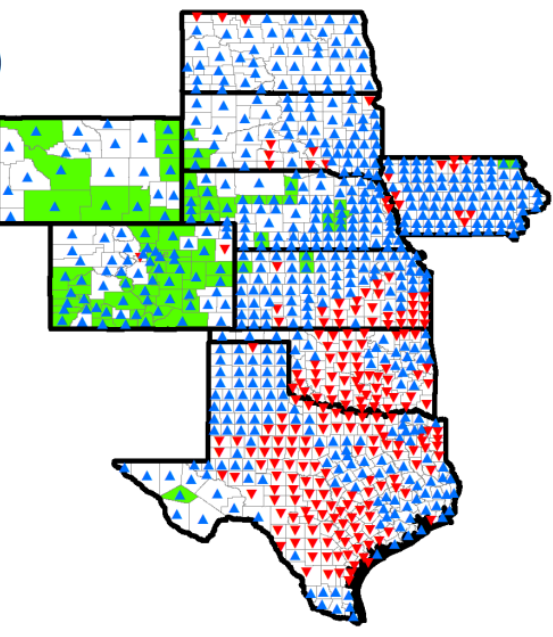

e)

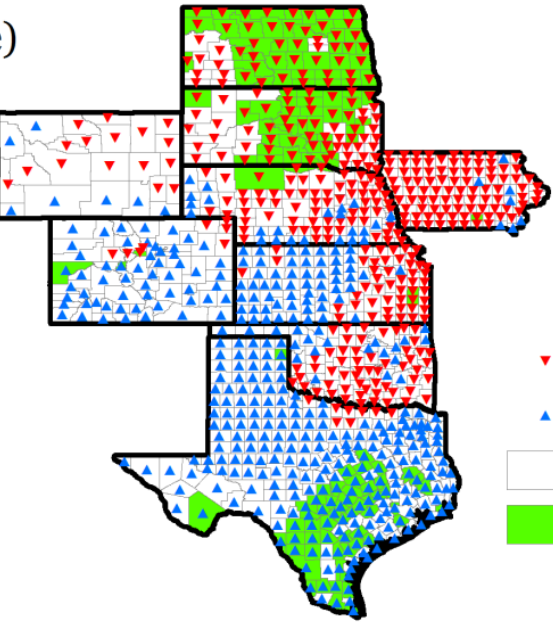

b)

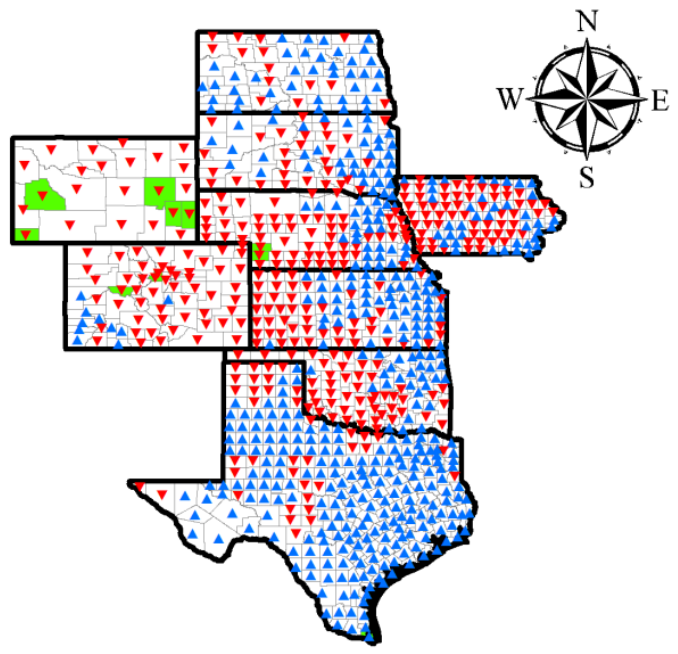

d)

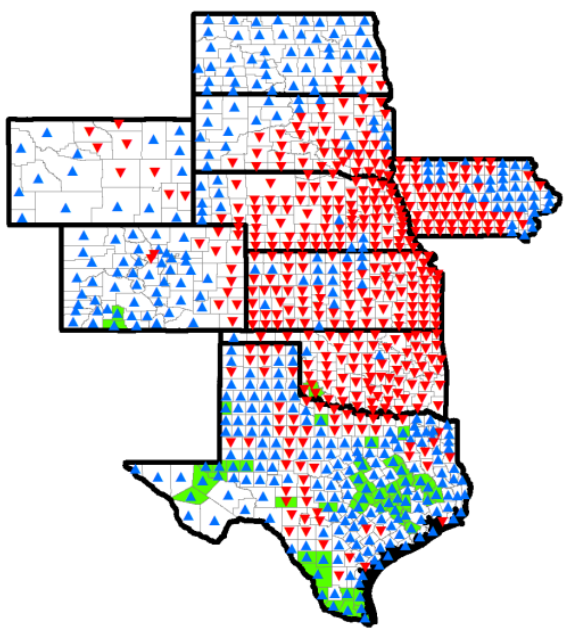

f)

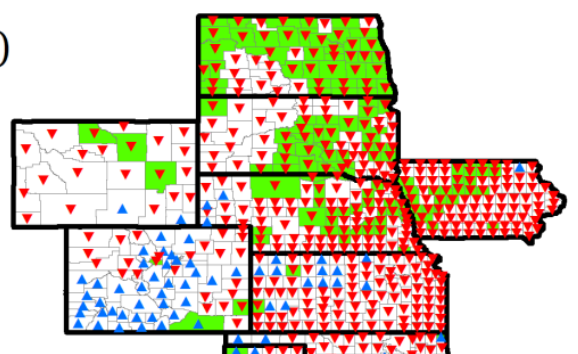

Decreasing trend

Increasing trend

Non-significant

Significant

O 290580

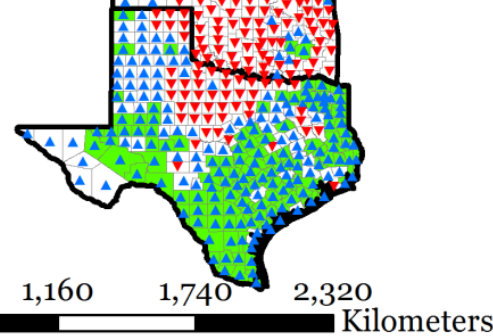

Figure 3. Nature, statistical significance and spatial distribution of county-based trends in $T_{\max }$ for a) January b) February, c) March, d) April, e) May, f) June, g) July, h) August, i) September, j) October, k) November, 1) December. 
g)

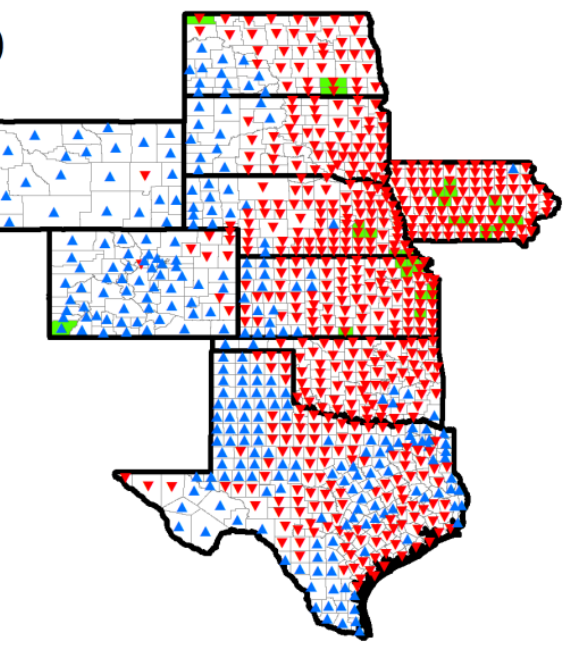

i)

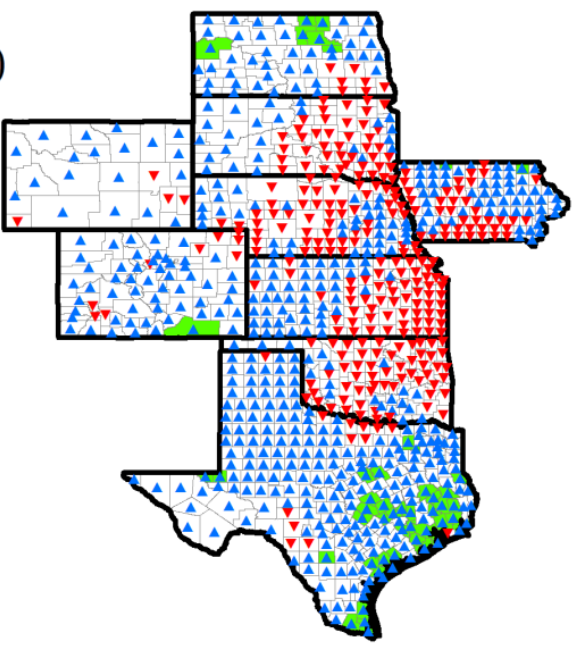

k)

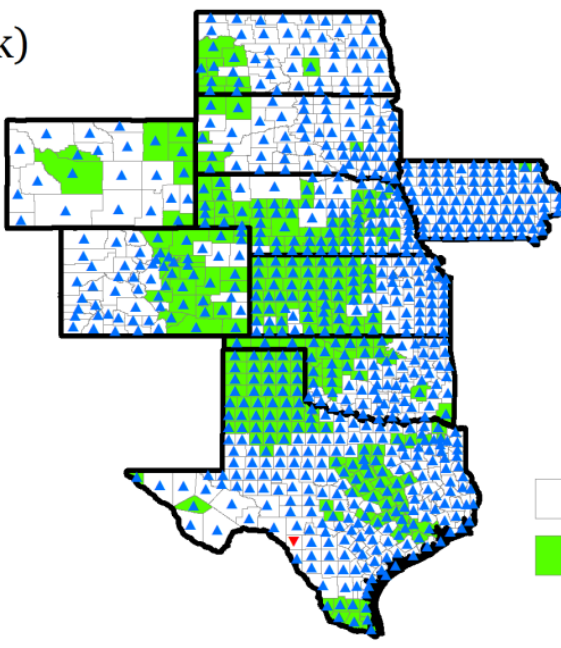

h)
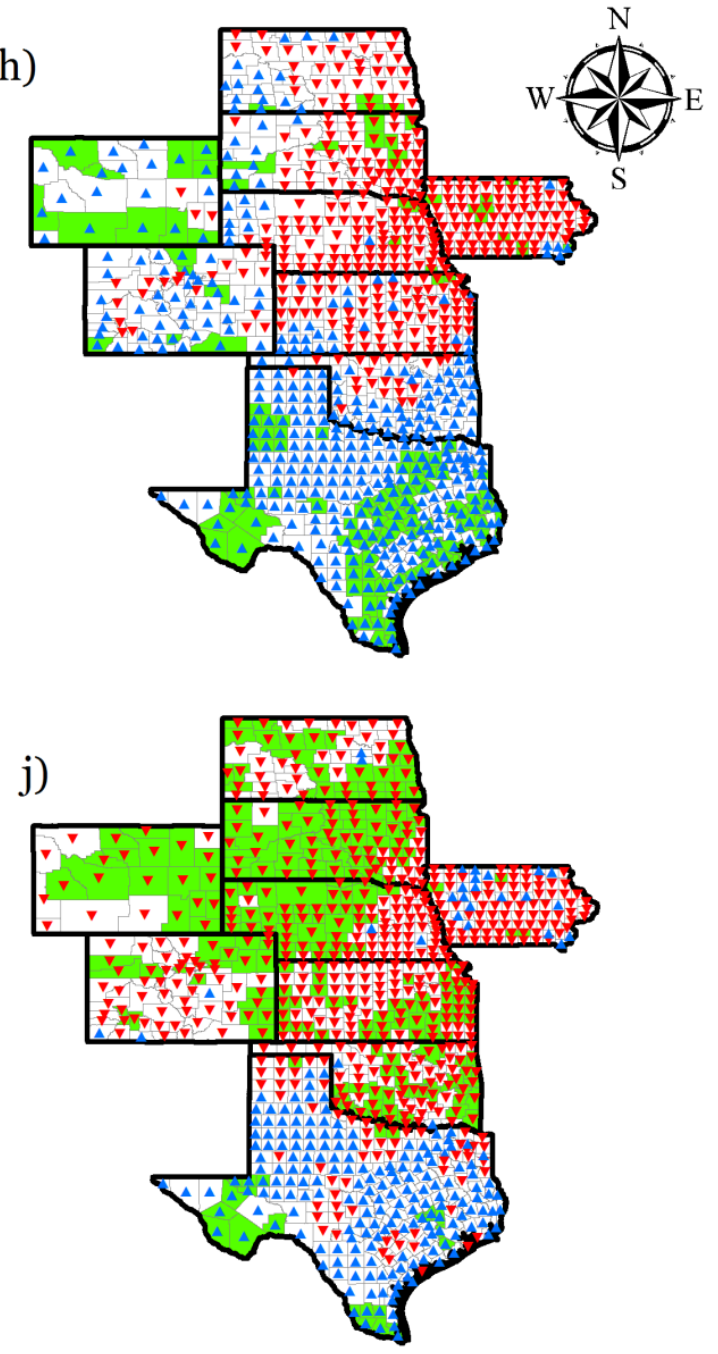

- Decreasing trend

$\triangle \quad$ Increasing trend

Non-significant

Significant

$$
0290580
$$

1)

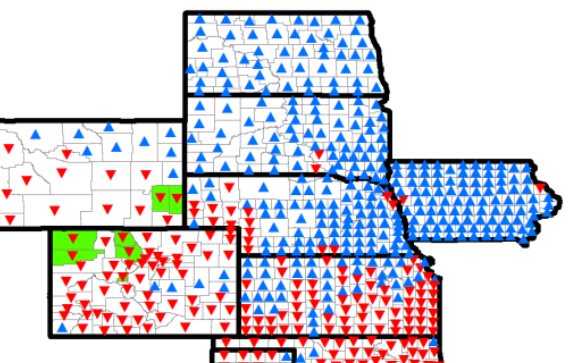

Figure 3 (cont.). Nature, statistical significance and spatial distribution of county-based trends in $T_{\max }$ for a) January b) February, c) March, d) April, e) May, f) June, g) July, h) August, i) September, j) October, k) November, 1) December. 


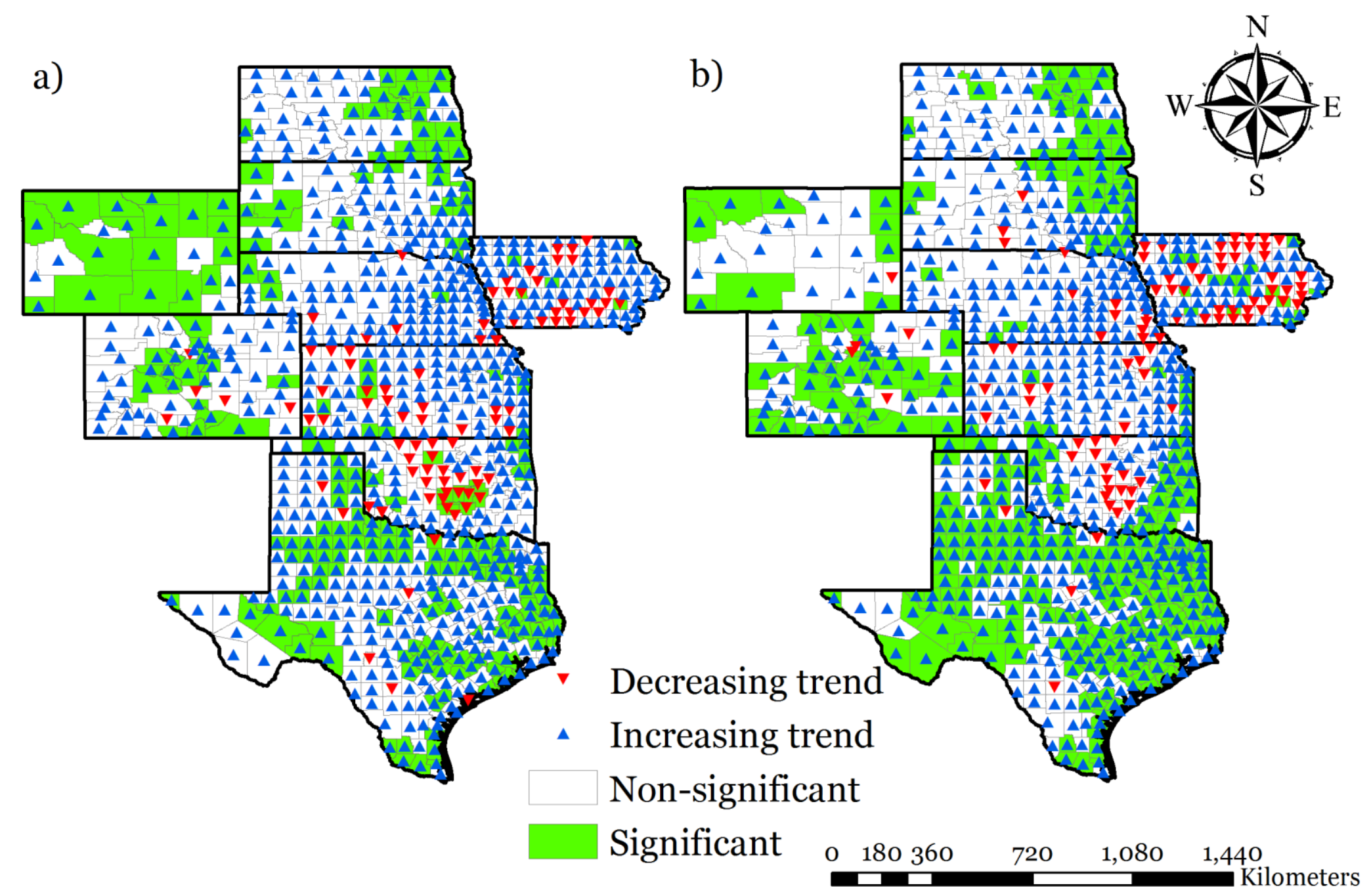

Figure 4. Spatial distribution and statistical significance of county-based trends in $\mathrm{T}_{\min }$ on a) Annual b) Growing-season basis. 
a)

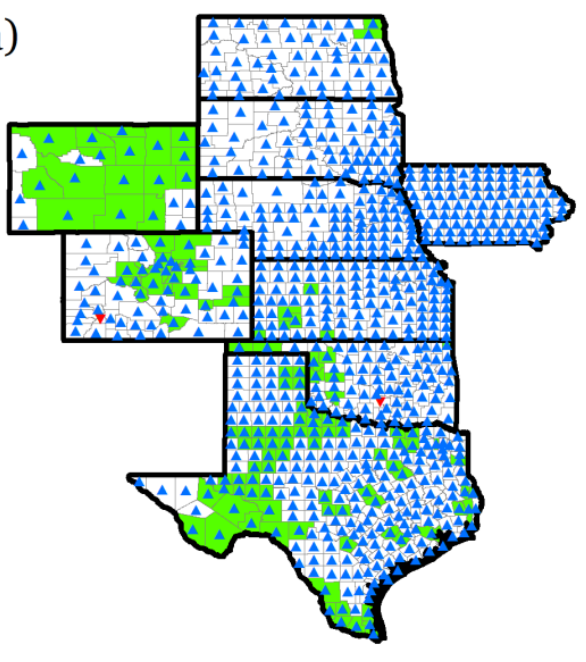

c)

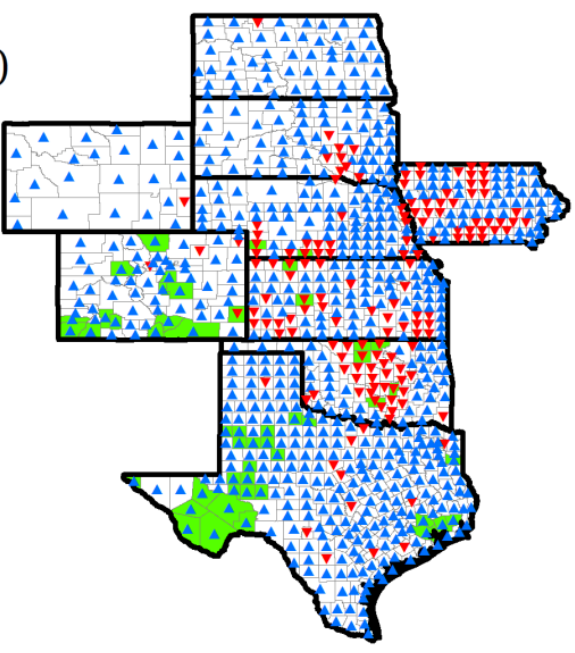

e)

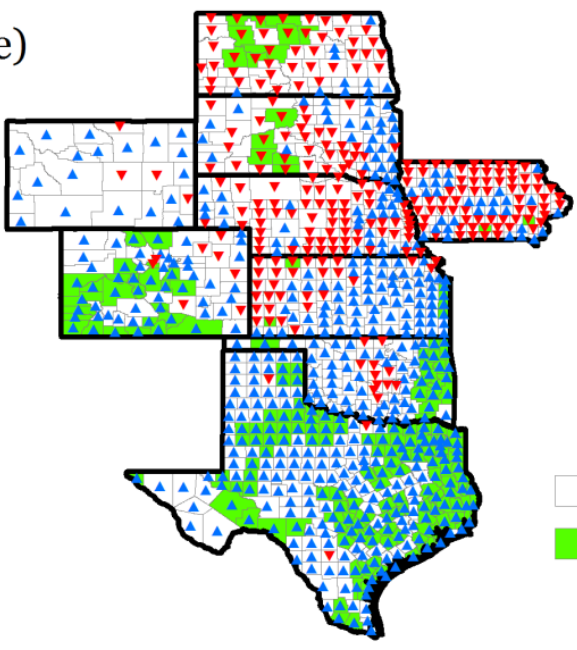

b)

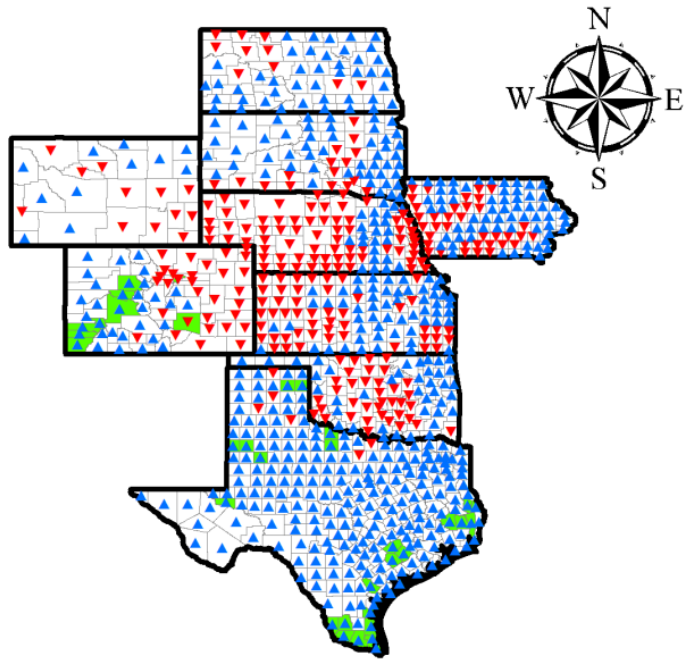

d)

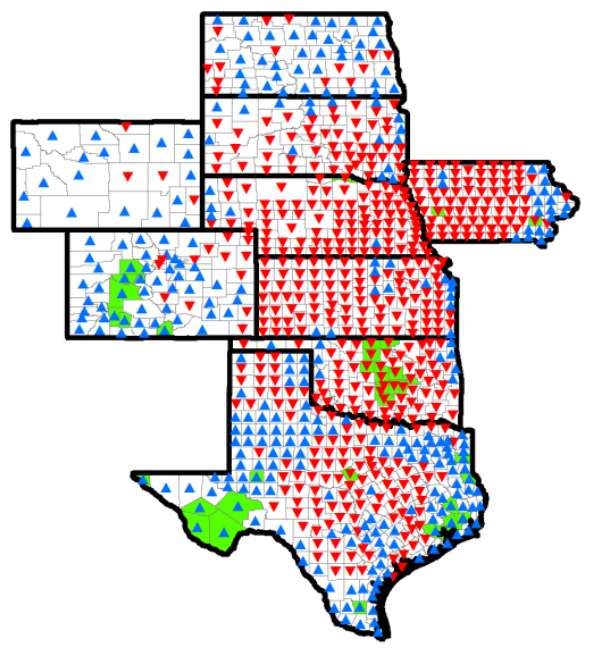

- Decreasing trend

Increasing trend

Non-significant

Significant

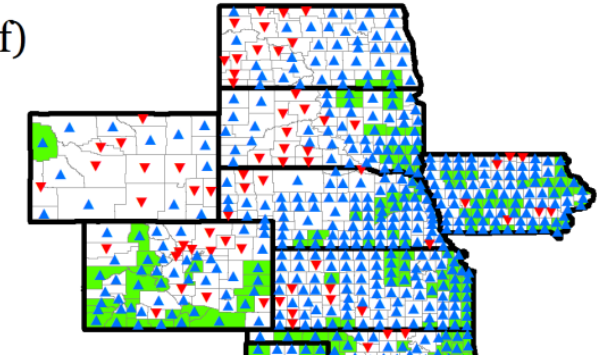

\section{$\begin{array}{llll}0 & 290580 \quad 1,160 \quad 1,740 & & \end{array}$}

Figure 5. Spatial distribution and statistical significance of county-based trends in $T_{\min }$ for a) January $b$ ) February, c) March, d) April, e) May, f) June, g) July, h) August, i) September, j) October, k) November, 1) December. 
g)

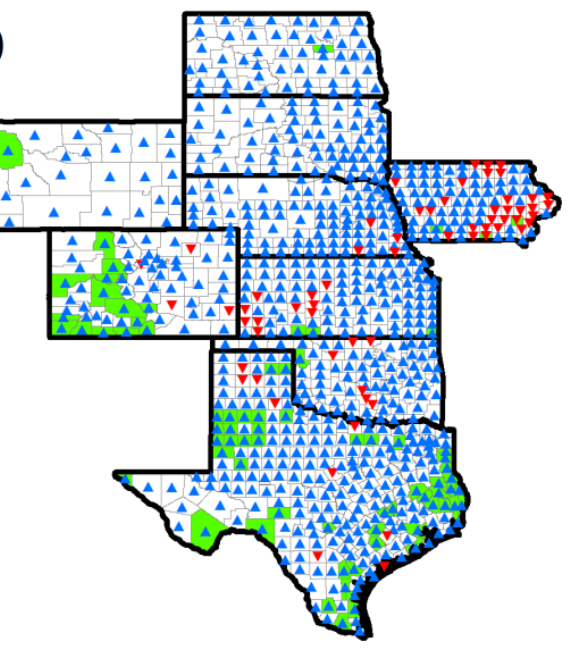

i)

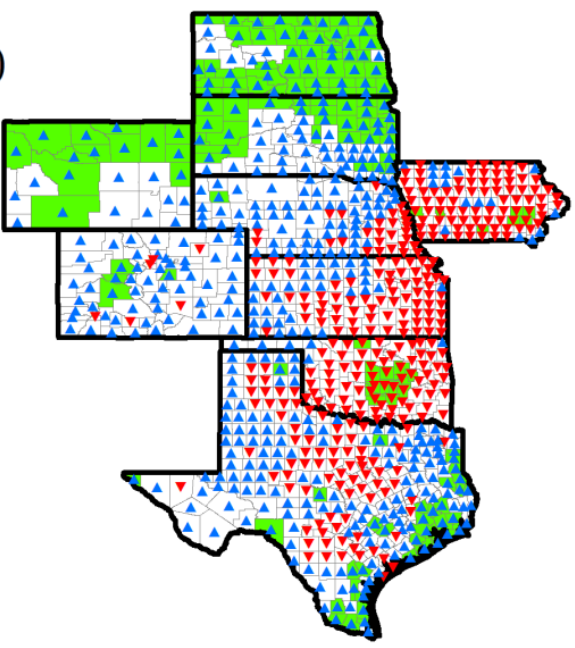

k)

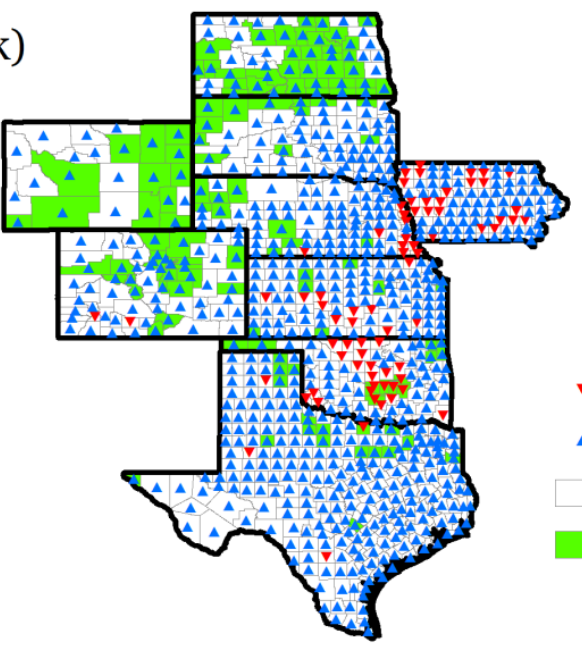

h)
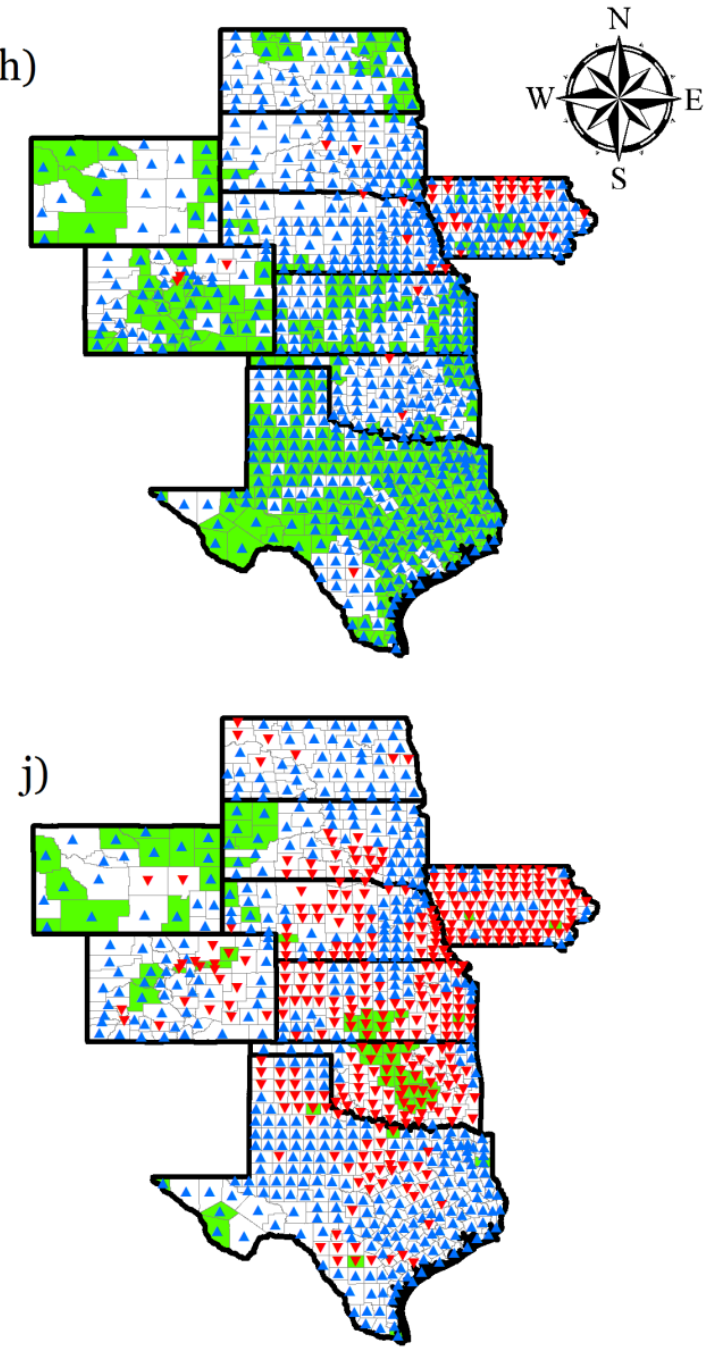

- Decreasing trend

$\triangle$ Increasing trends

Non-significant

Significant

$$
\text { o } 290580
$$

1)

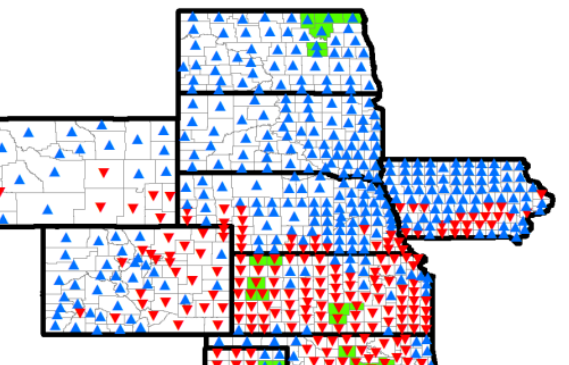

Figure 5 (cont.). Spatial distribution and statistical significance of county-based trends in $\mathrm{T}_{\min }$ for a) January b) February, c) March, d) April, e) May, f) June, g) July, h) August, i) September, j) October, k) November, 1) December. 


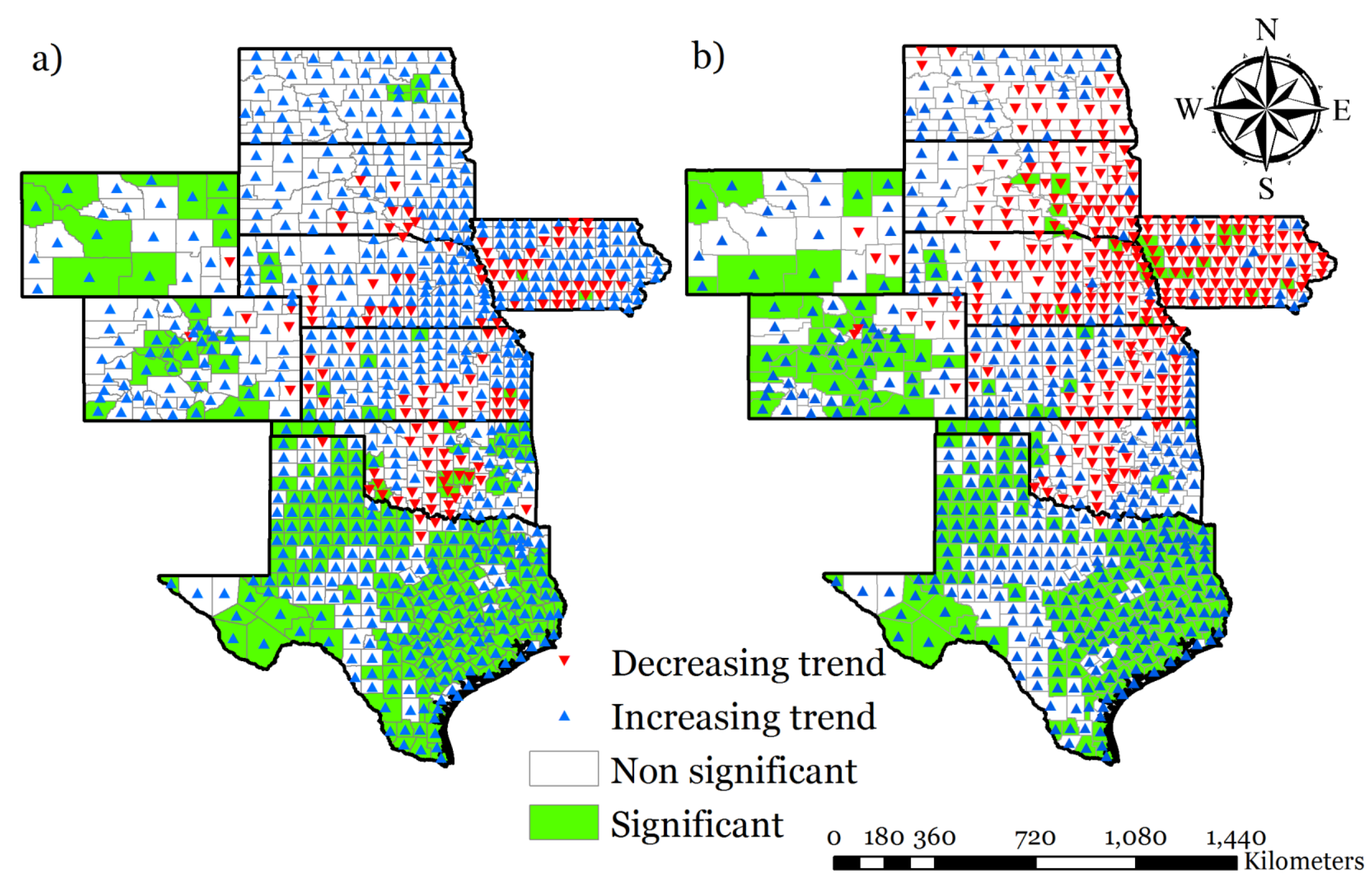

Figure 6. Spatial distribution and statistical significance of county-based trends in $T_{\text {avg }}$ on a) Annual b) Growing-season basis. 
a)

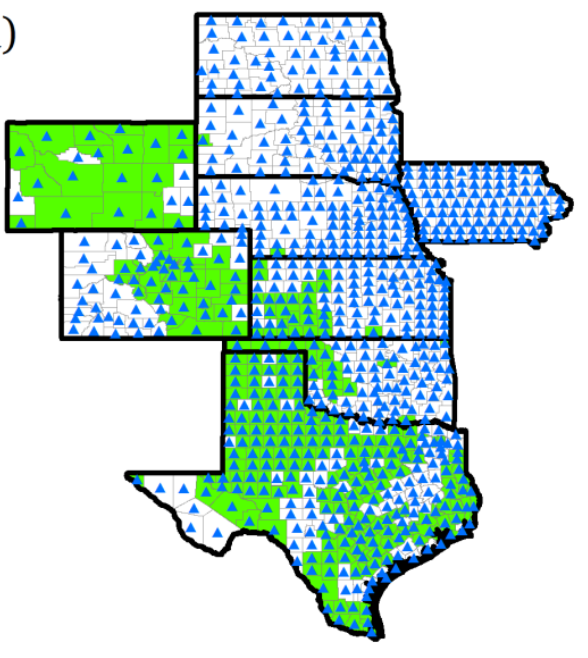

c)

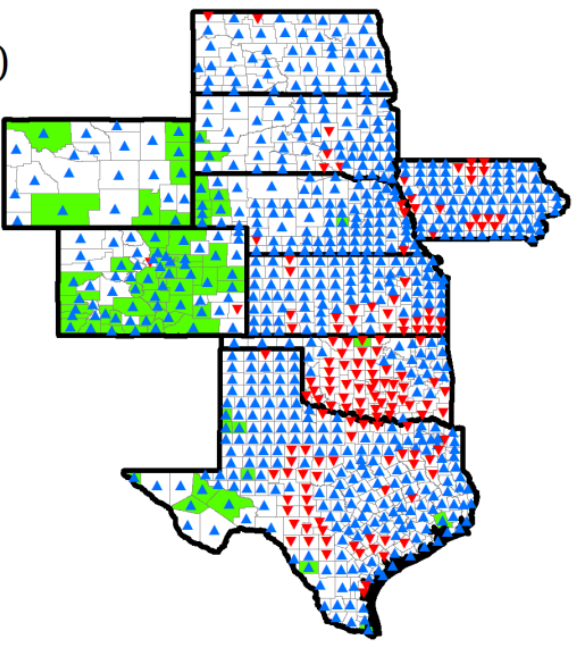

e)

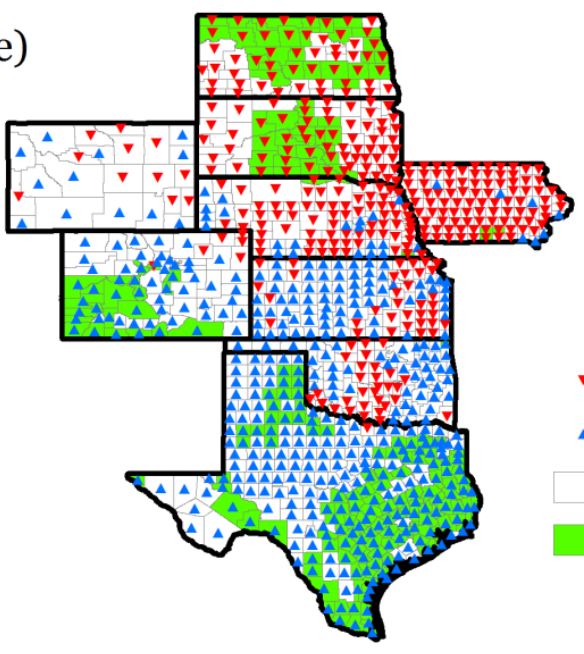

b)

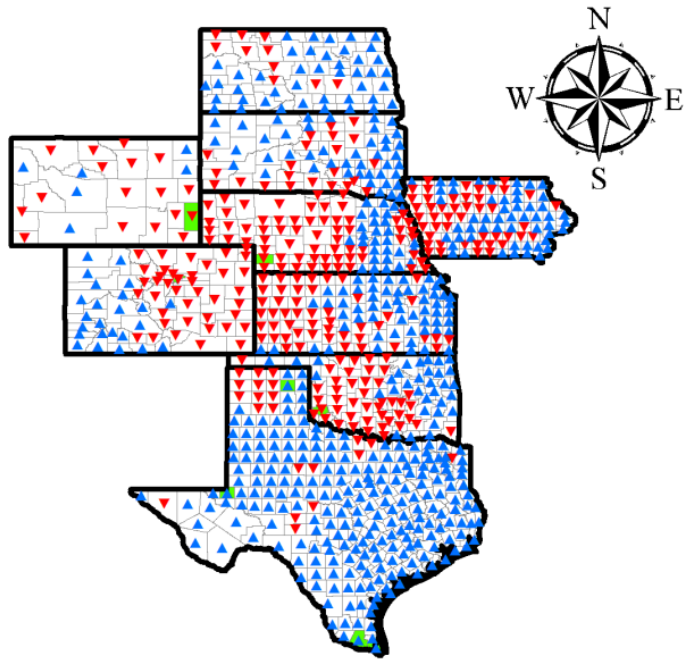

d)

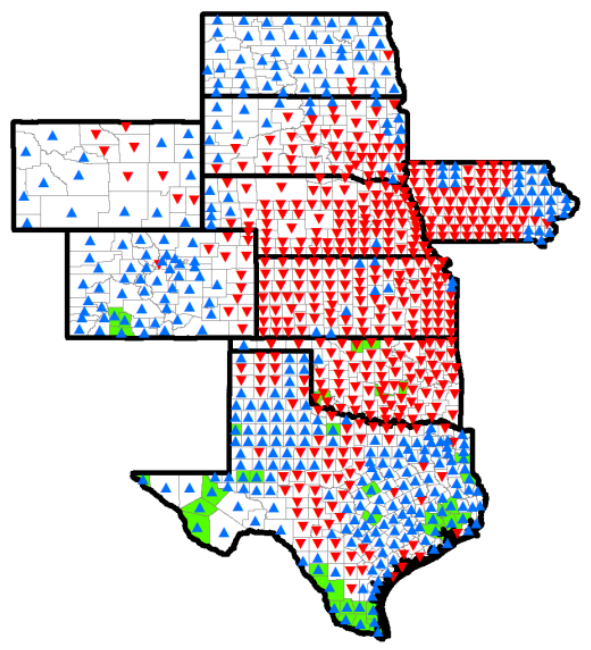

- Decreasing trend

Increasing trend Non-significant Significant

$0 \quad 290580 \quad 1,160 \quad 1,740 \quad 2,320$

Figure 7. Spatial distribution and statistical significance of county-based trends in $T_{\text {avg }}$ for $\left.a\right)$ January $b$ ) February, c) March, d) April, e) May, f) June, g) July, h) August, i) September, j) October, k) November, 1) December. 

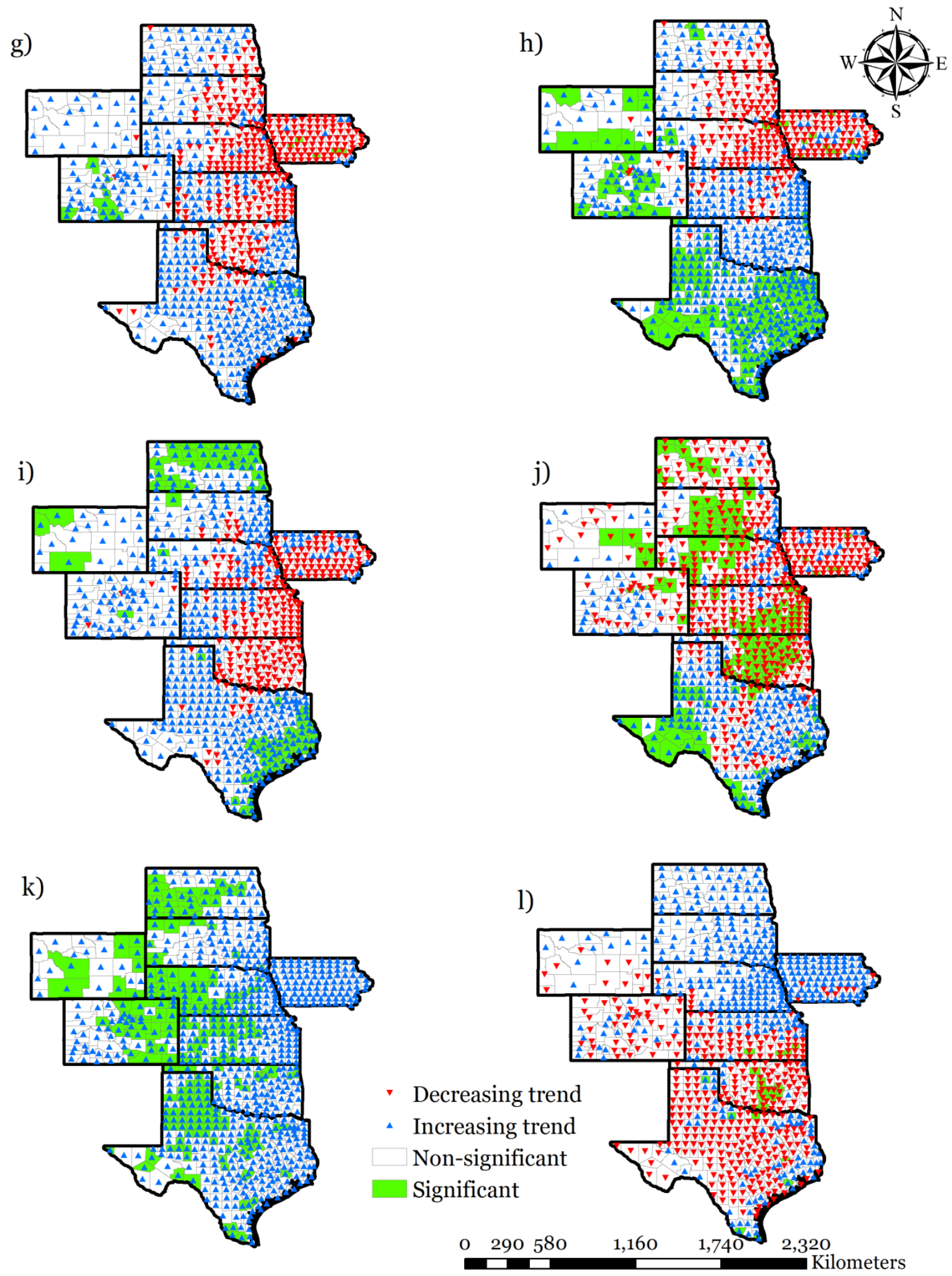

Figure 7 (cont.). Spatial distribution and statistical significance of county-based trends in $\mathrm{T}_{\text {avg }}$ for a) January b) February, c) March, d) April, e) May, f) June, g) July, h) August, i) September, j) October, k) November, 1) December. 


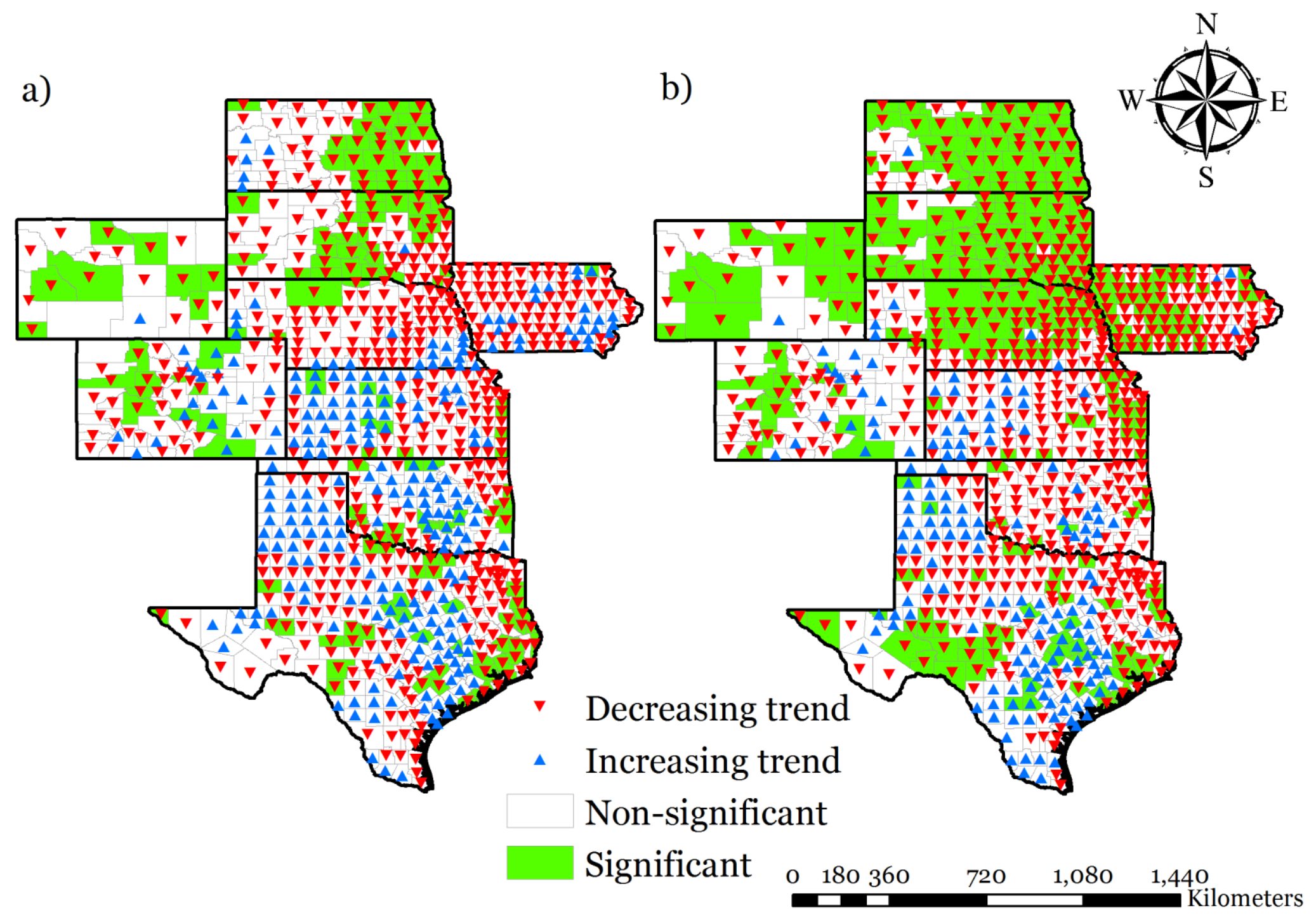

Figure 8. Spatial distribution and statistical significance of county-based trends in DTR on a) Annual b) Growing-season basis. 
a)
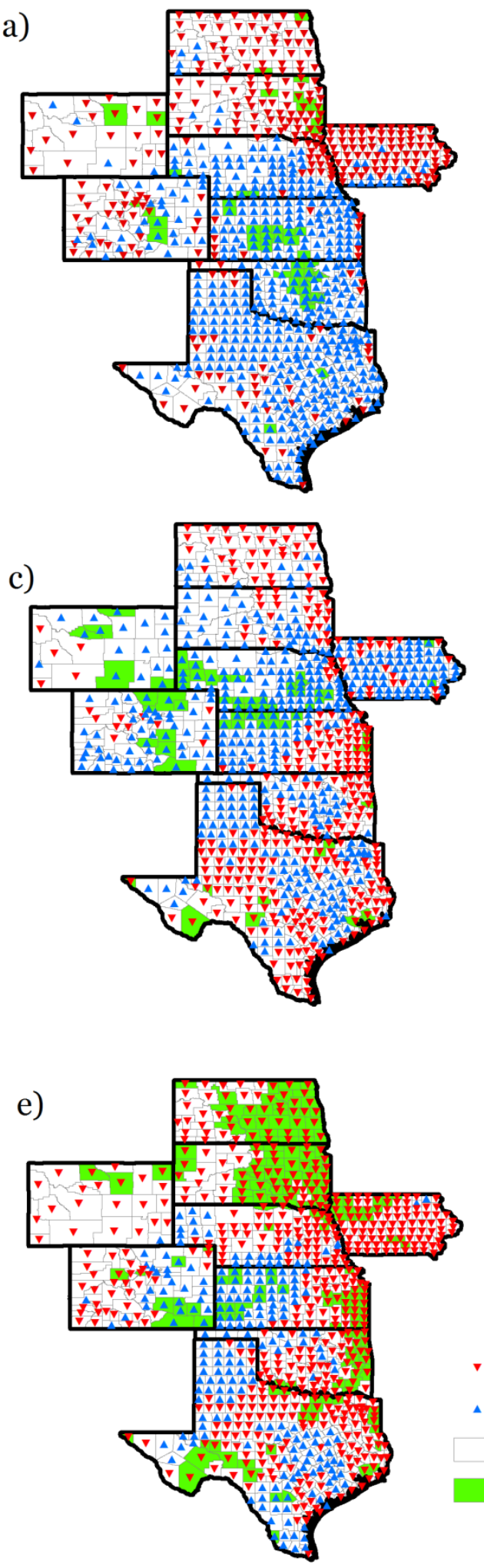

b)

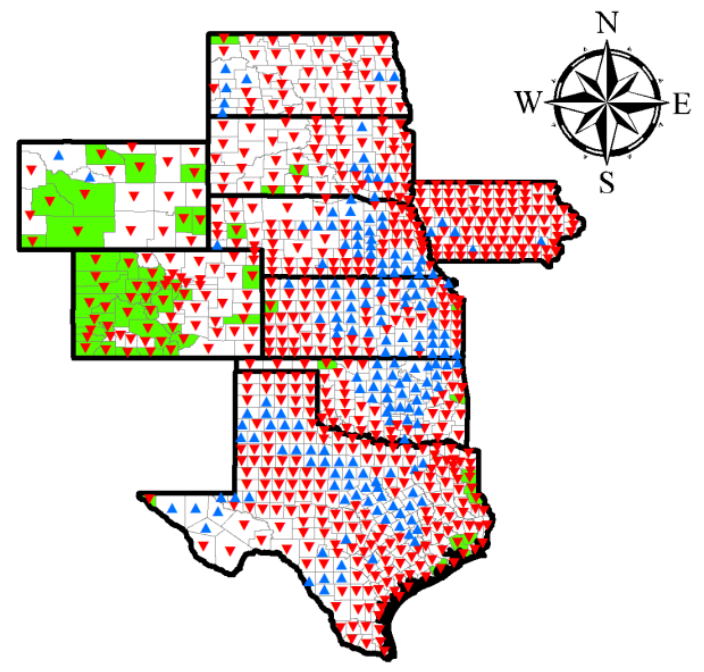

d)

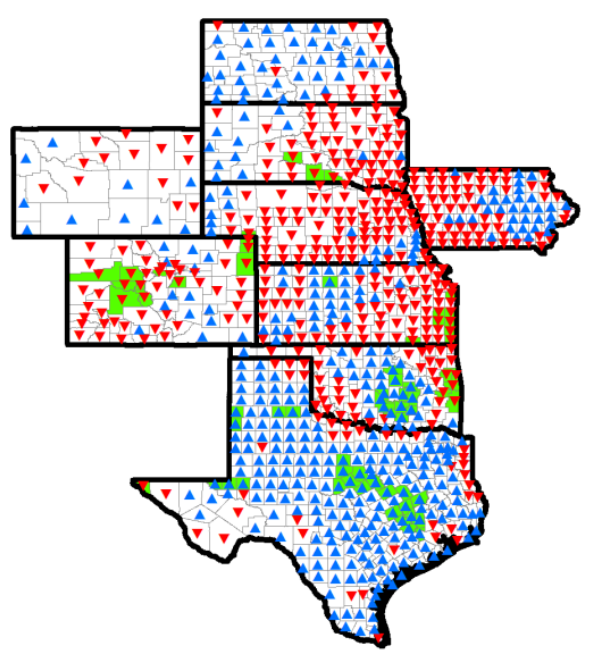

Decreasing trend

Increasing trend Non-significant Significant

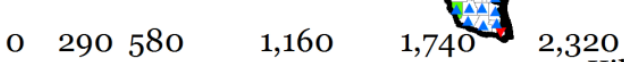

Figure 9. Spatial distribution and statistical significance of county-based trends in DTR for a) January b) February, c) March, d) April, e) May, f) June, g) July, h) August, i) September, j) October, k) November, 1) December. 
g)

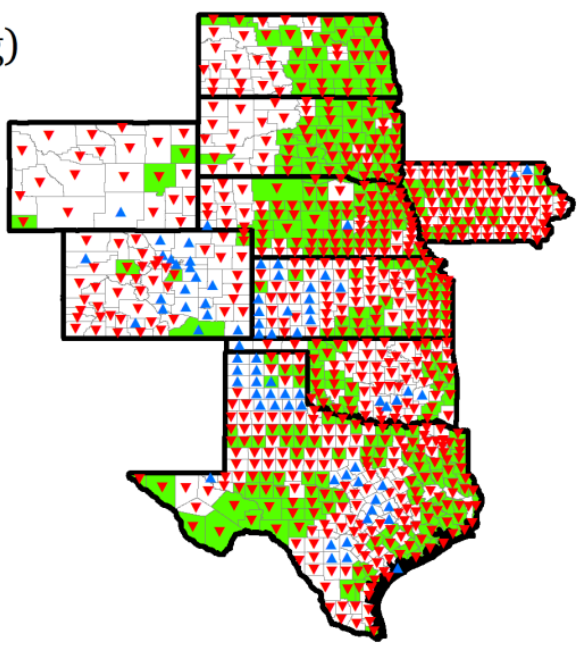

i)

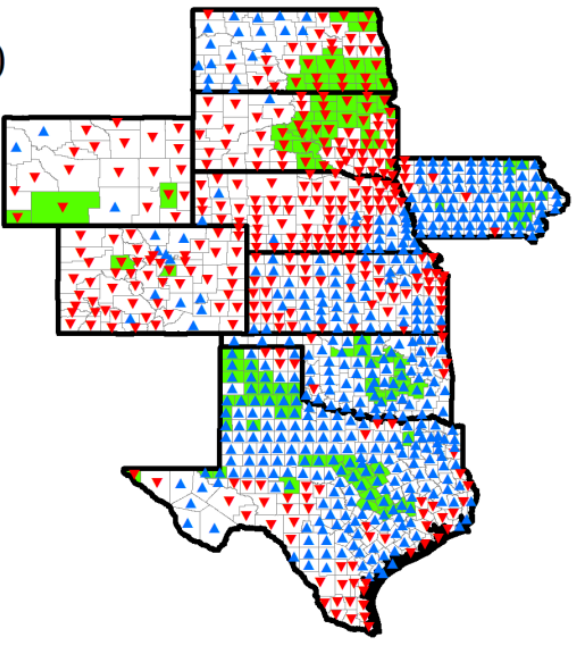

k)

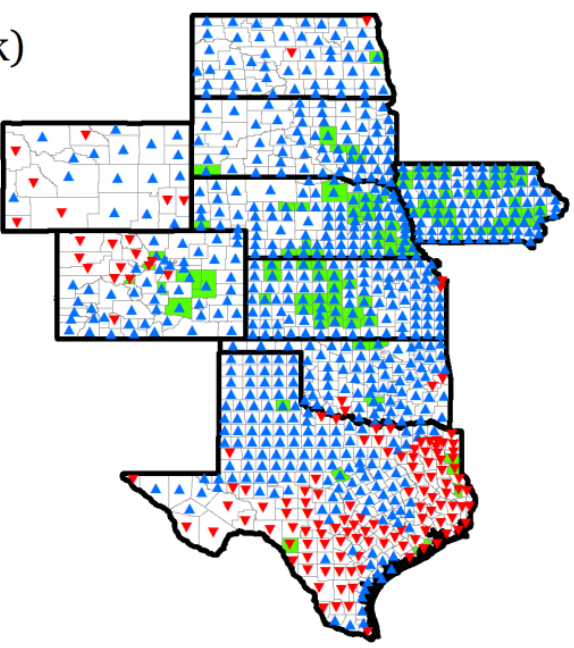

h)

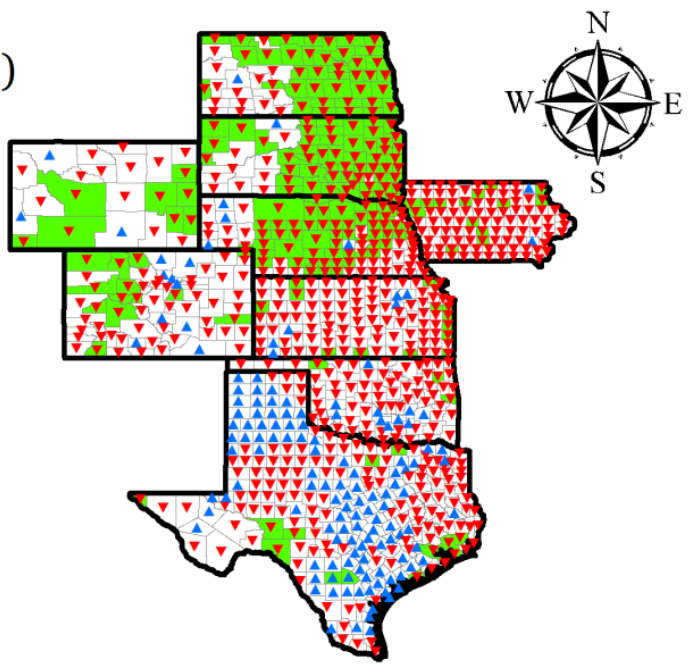

j)

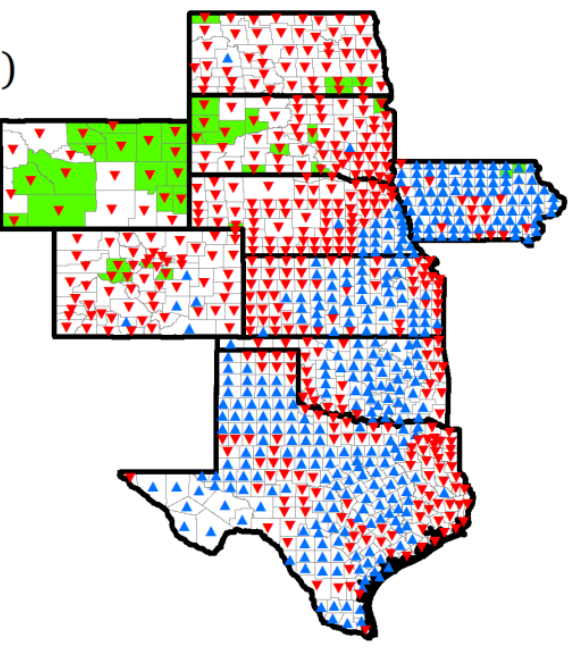

1)

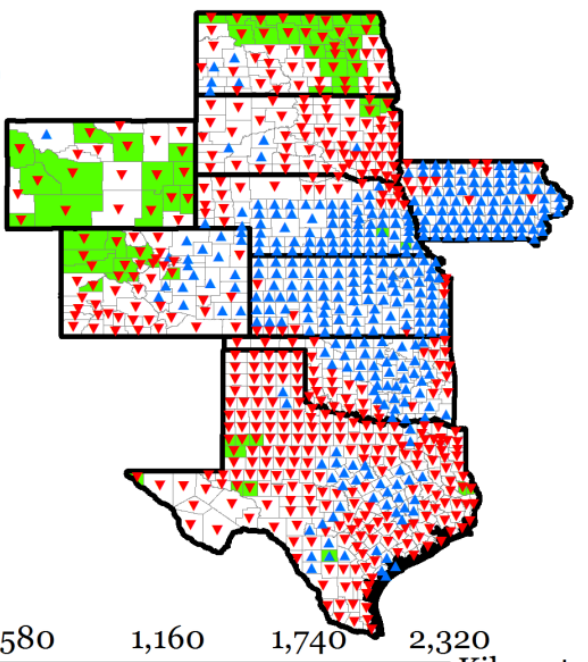

Figure 9 (cont.). Spatial distribution and statistical significance of county-based trends in DTR for a) January b) February, c) March, d) April, e) May, f) June, g) July, h) August, i) September, j) October, k) November, 1) December. 


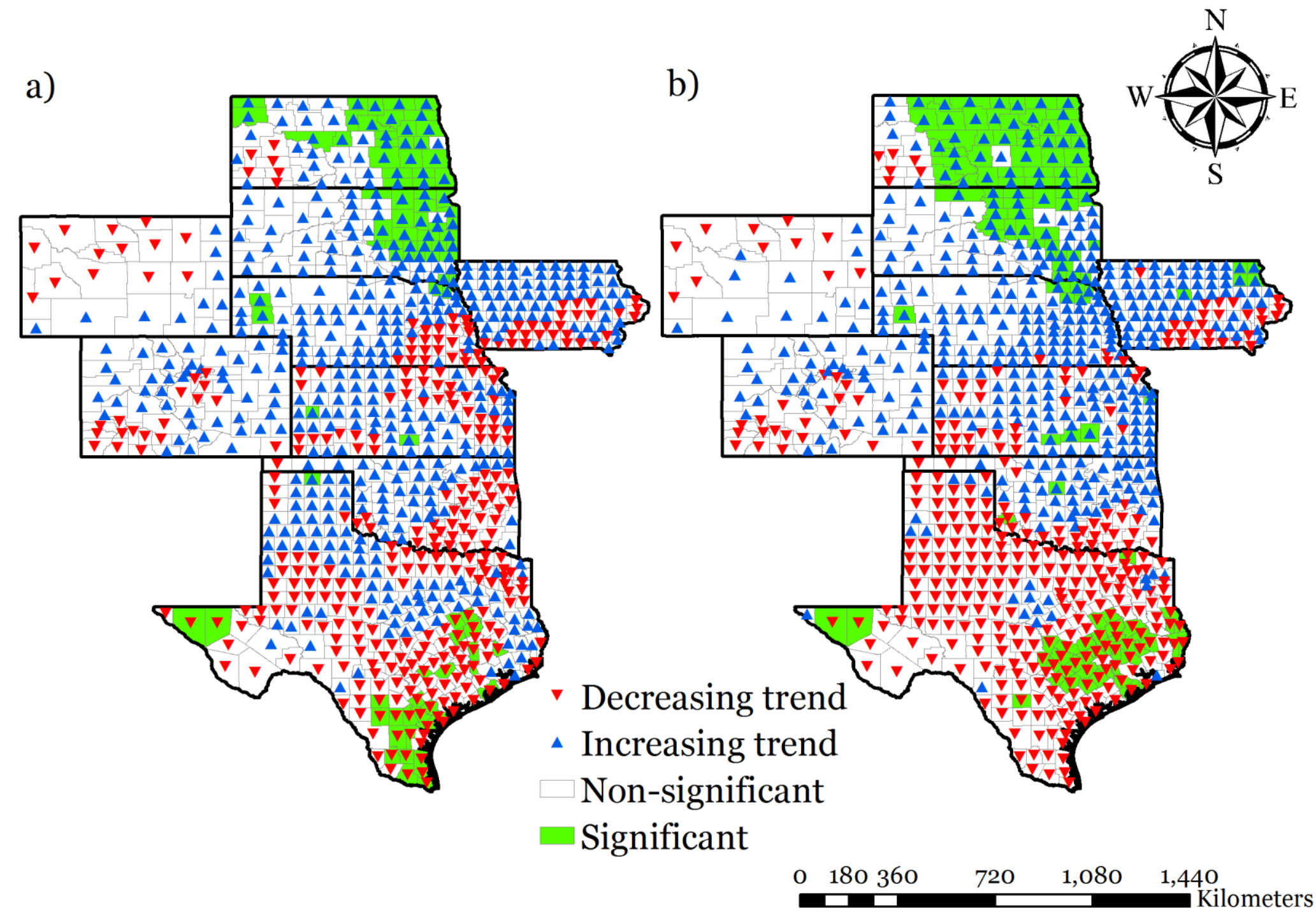

Figure 10. Spatial distribution and statistical significance of county-based trends in precipitation on a) Annual b) Growing-season basis. 
a)

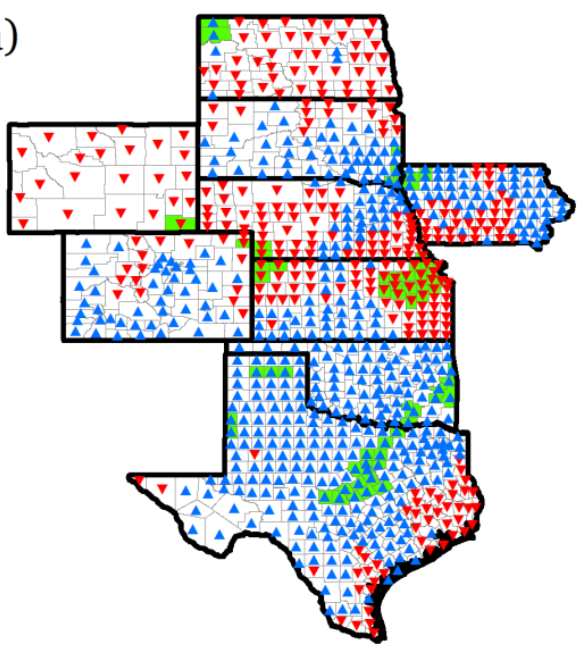

c)

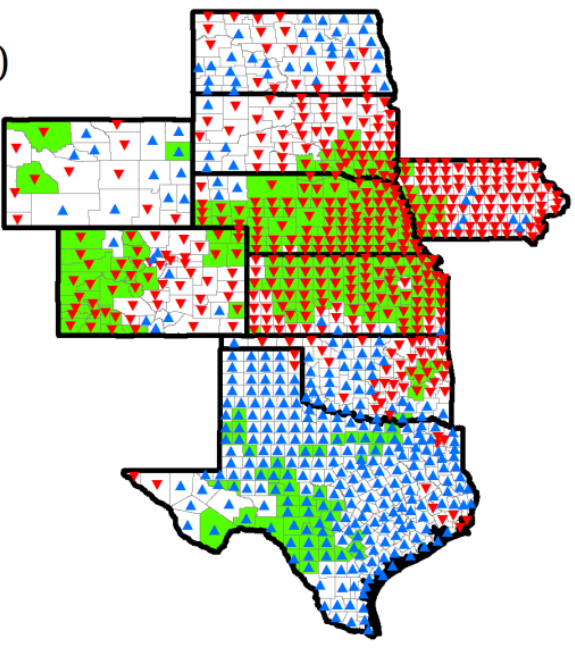

e)

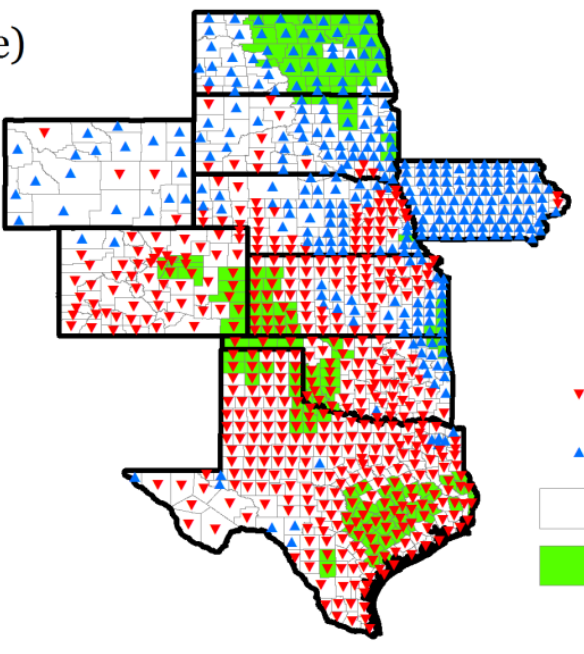

b)

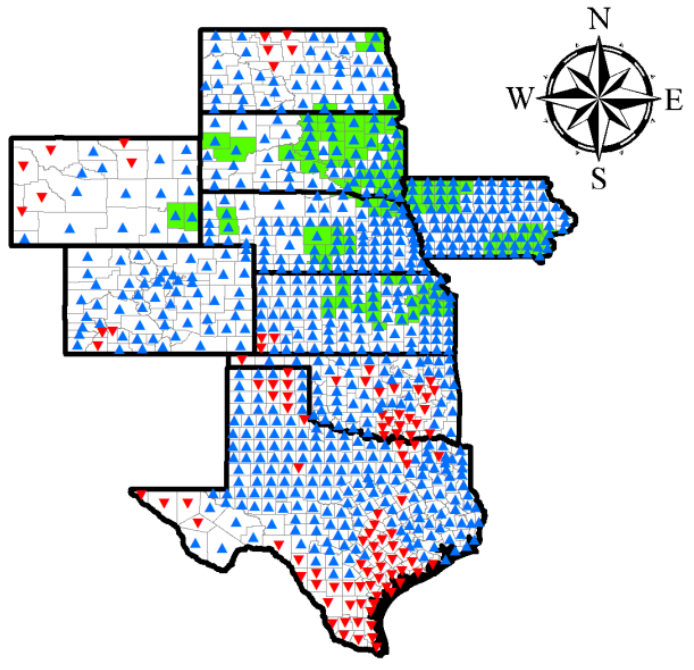

d)

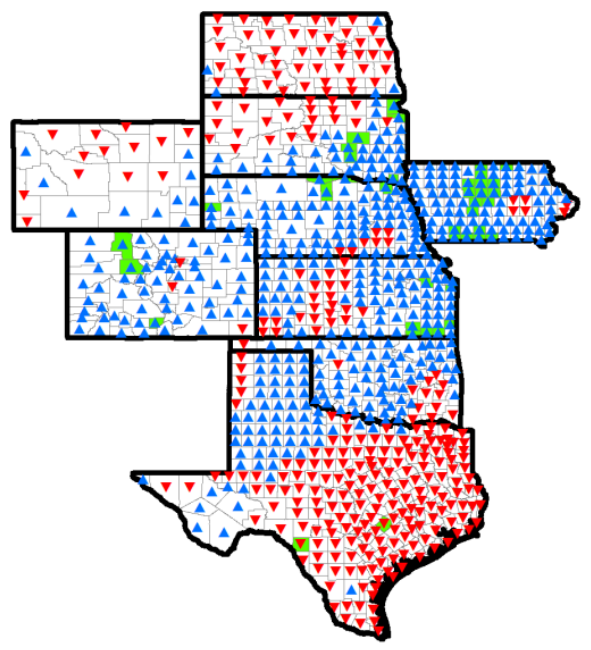

f)

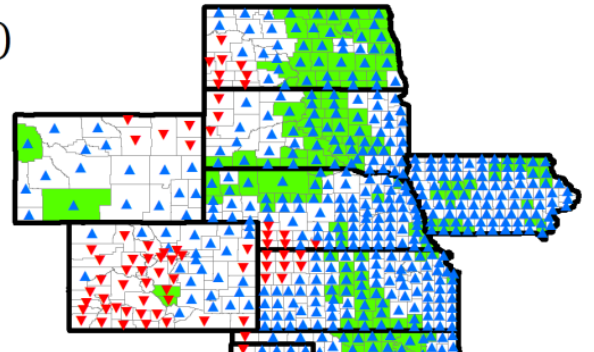

- Decreasing trend

$\triangle \quad$ Increasing trend Non-significant Significance

$$
\begin{array}{lllll}
0 & 290580 \quad 1,160 \quad 1,740 &
\end{array}
$$

Figure 11. Spatial distribution and statistical significance of county-based trends in precipitation for a) January b) February, c) March, d) April, e) May, f) June, g) July, h) August, i) September, j) October, k) November, 1) December. 
g)

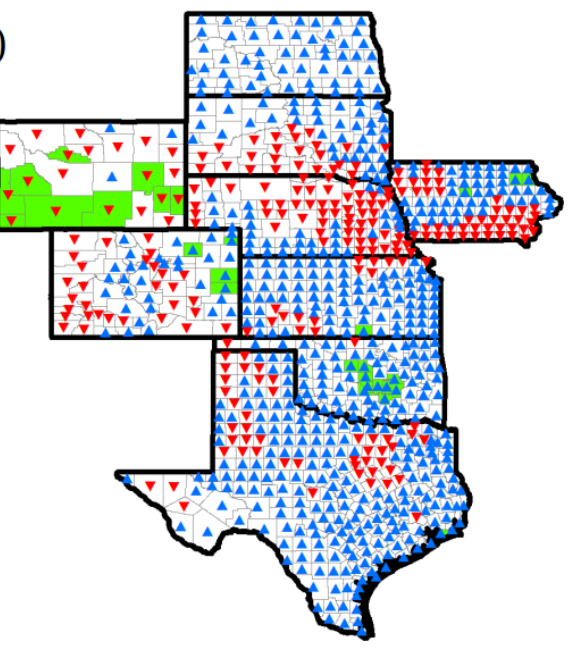

i)

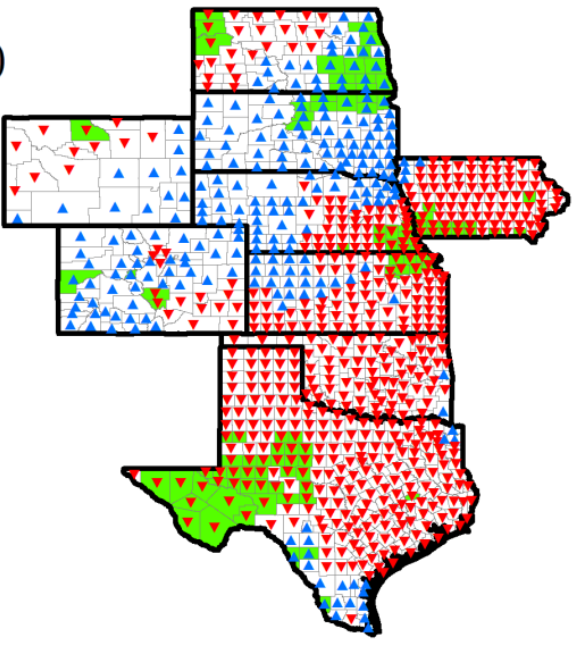

k)

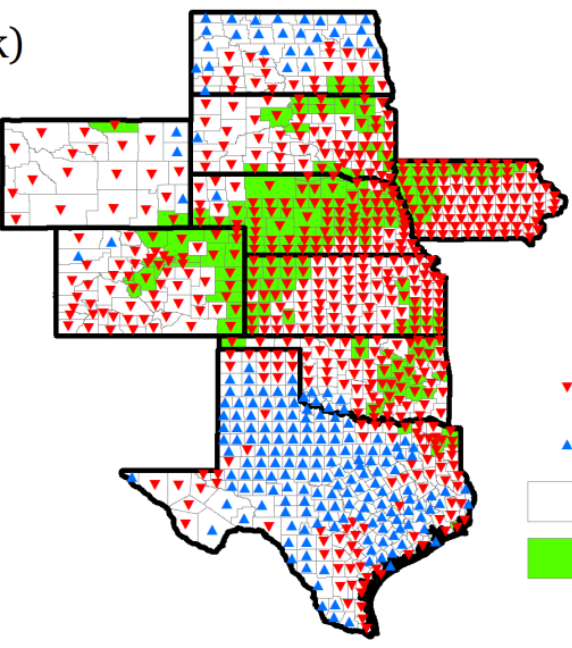

h)
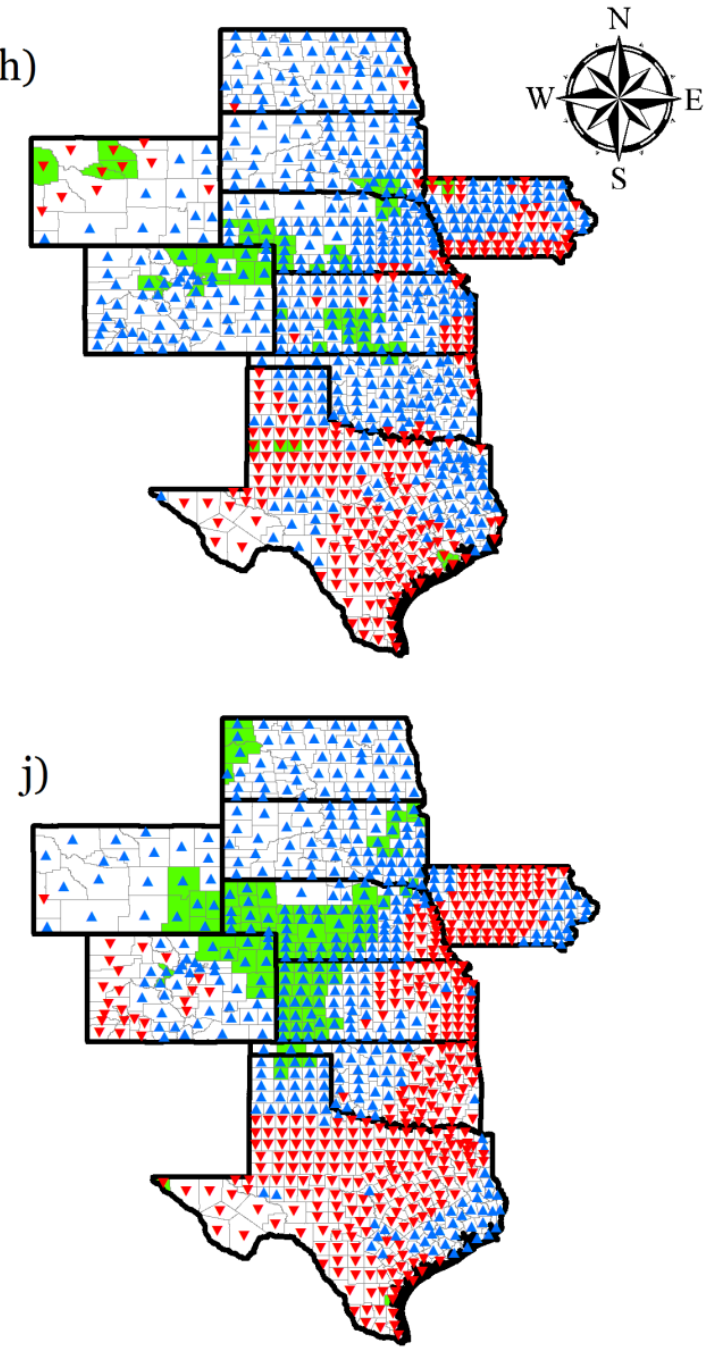

1)

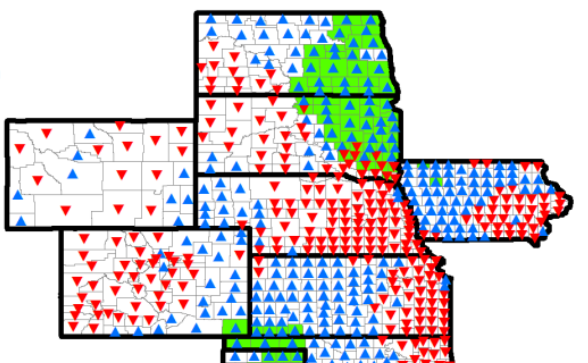

- Decreasing trend

$\triangle \quad$ Increasing trend Non-significant Significant

$$
\text { o } 290580
$$

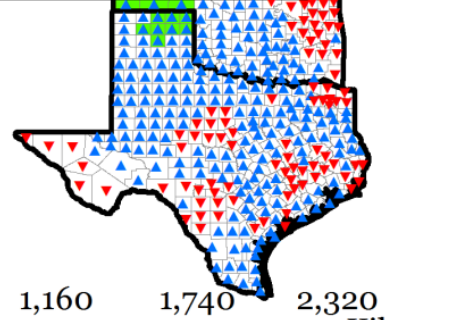

Figure 11 (cont.). Spatial distribution and statistical significance of county-based trends in precipitation for a) January b) February, c) March, d) April, e) May, f) June, g) July, h) August, i) September, j) October, k) November, l) December. 


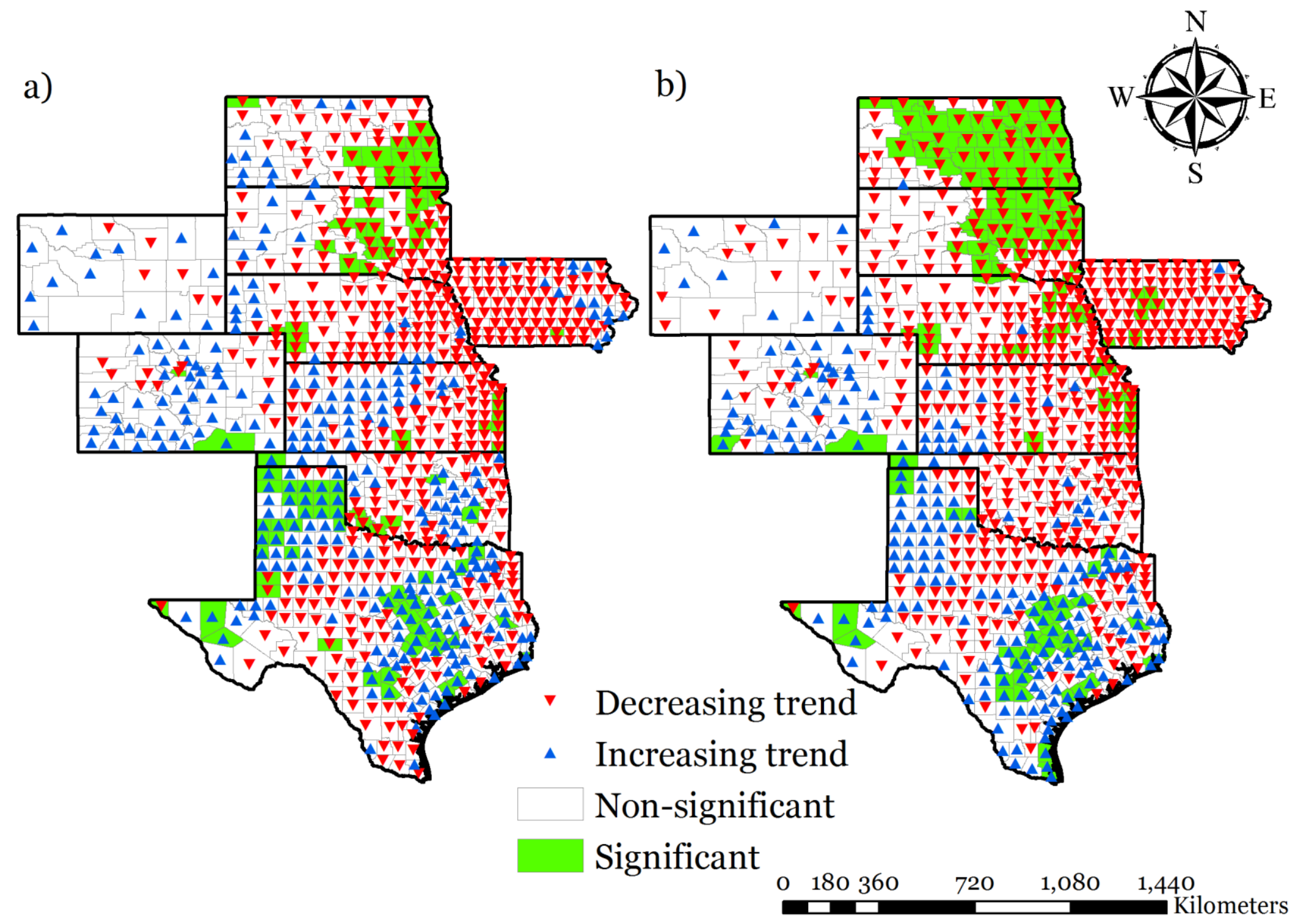

Figure 12. Spatial distribution and statistical significance of county-based trends in $\mathrm{ET}_{\mathrm{o}}$ on a) Annual b) Growing-season basis. 
a)

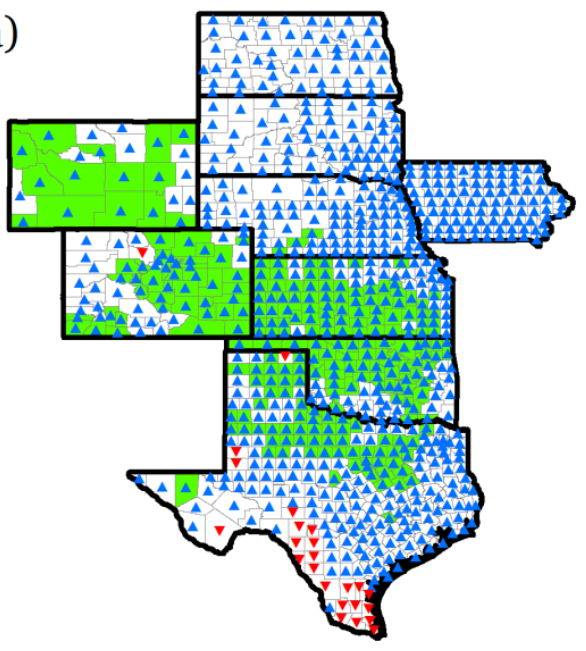

c)

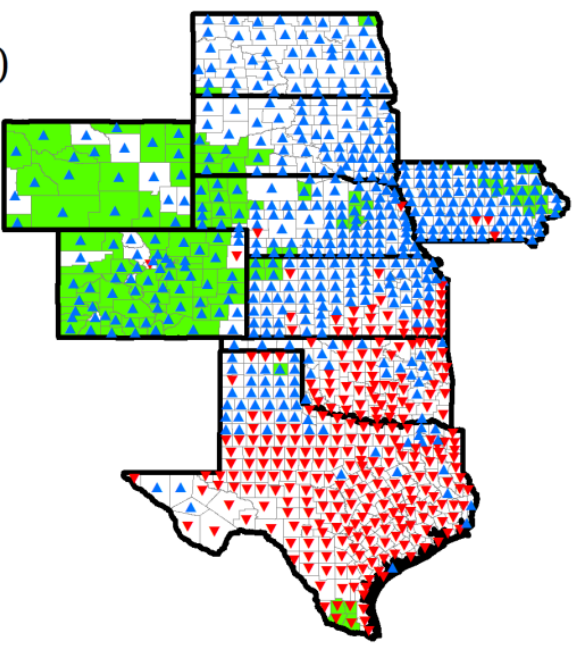

e)

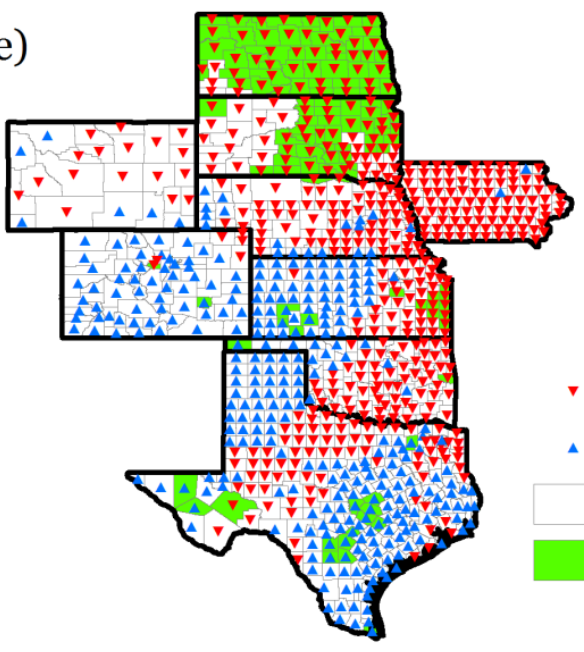

b)

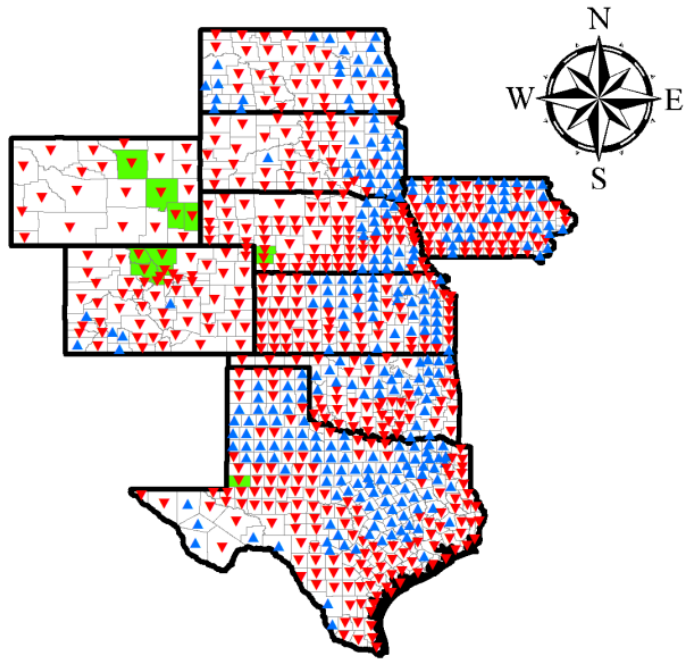

d)

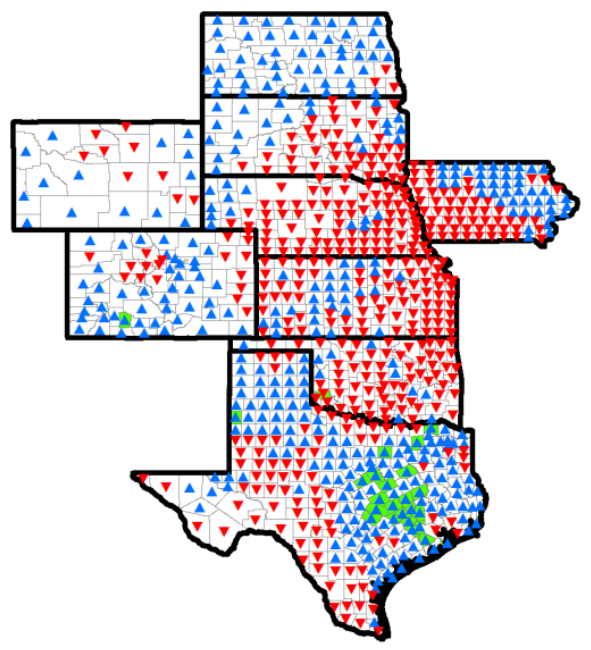

Decreasing trend

$\triangle \quad$ Increasing trend Non-significant Significant

$$
0.290580
$$

f)

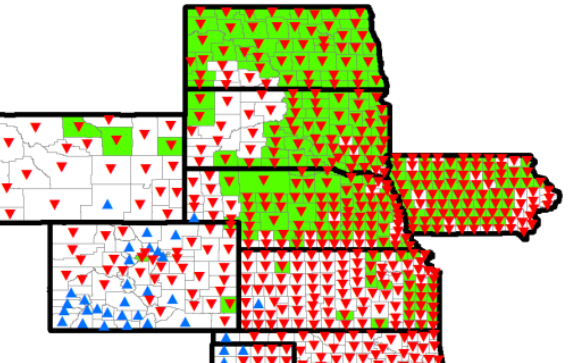

Figure 13. Spatial distribution and statistical significance of county-based trends in $E_{0}$ for a) January b) February, c) March, d) April, e) May, f) June, g) July, h) August, i) September, j) October, k) November, 1) December. 
g)

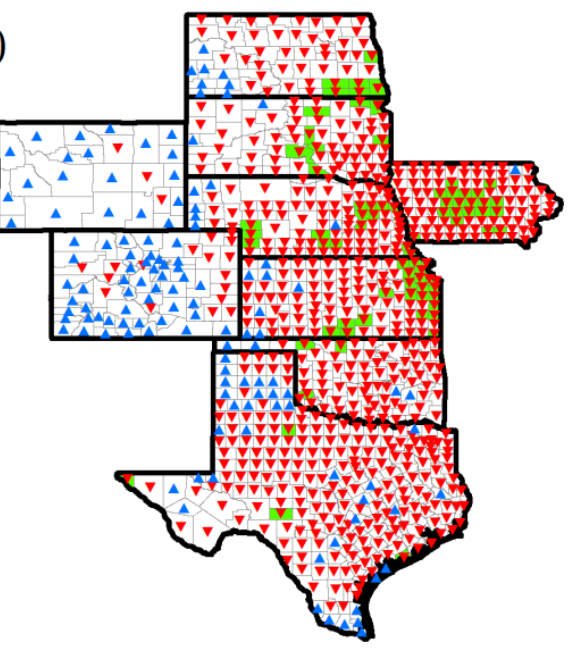

i)

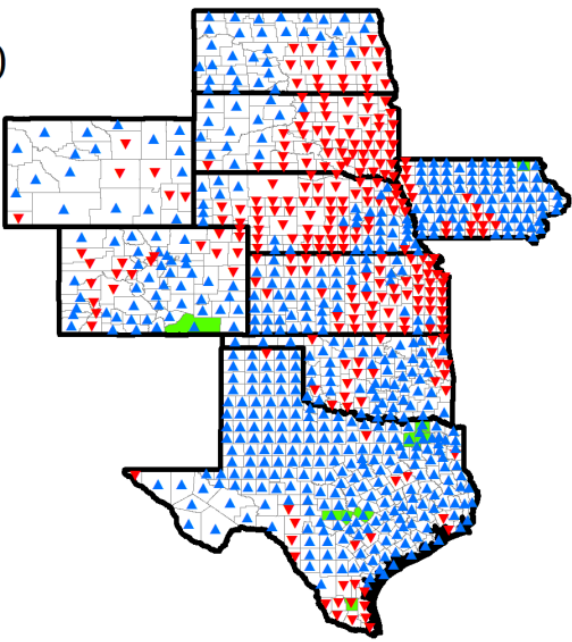

k)

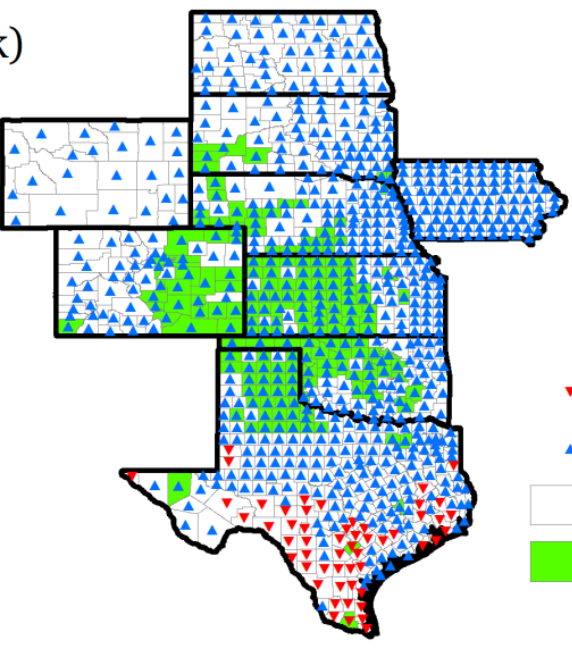

h)

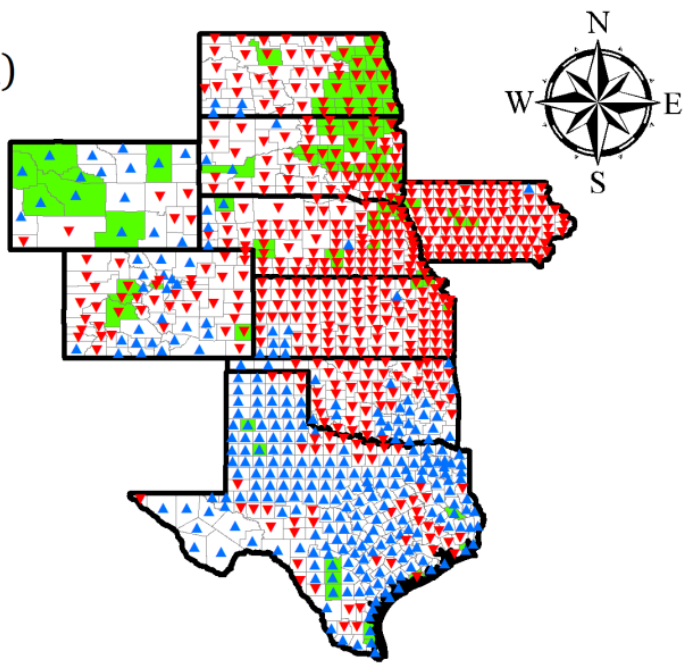

j)

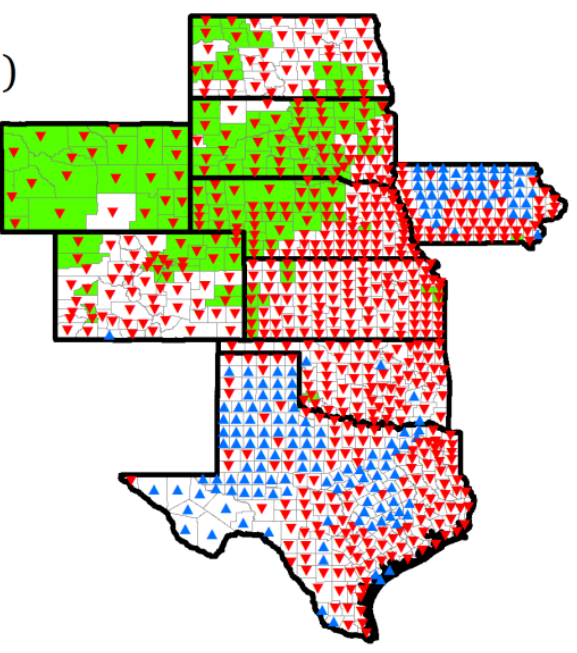

1)

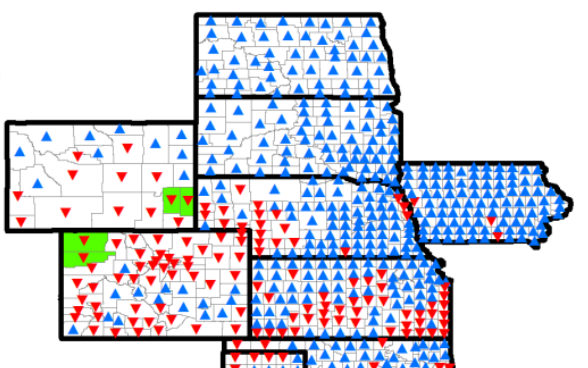

- Decreasing trend

- Increasing trend Non-significant Significant

$$
\text { o } 290580
$$

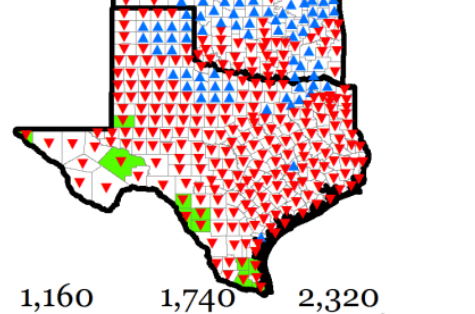

Figure 13 (cont.). Spatial distribution and statistical significance of county-based trends in $\mathrm{ET}_{\mathrm{o}}$ for a) January b) February, c) March, d) April, e) May, f) June, g) July, h) August, i) September, j) October, k) November, 1) December. 


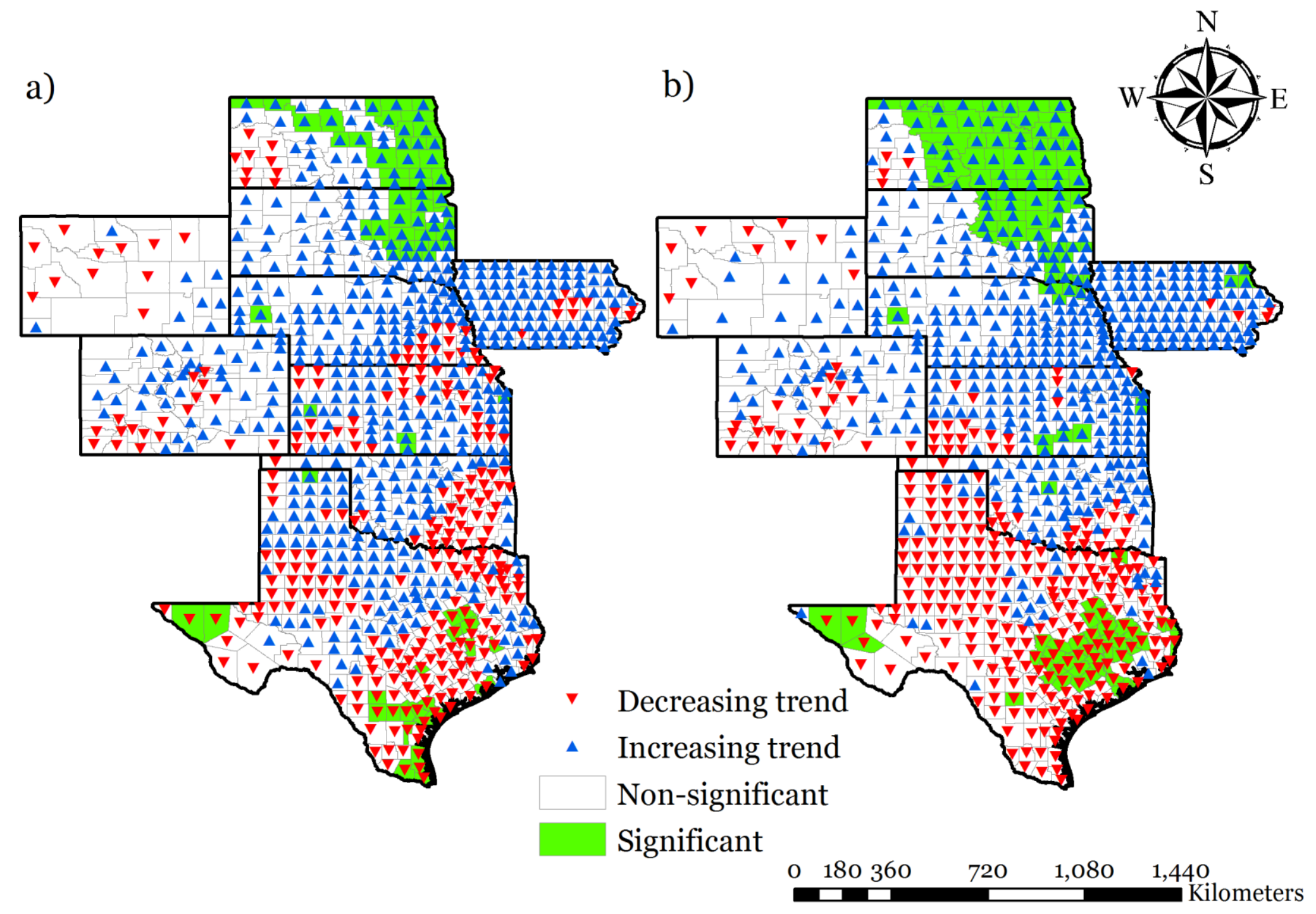

Figure 14. Spatial distribution and statistical significance of county-based trends in aridity index on a) Annual b) Growing-season basis. 
a)

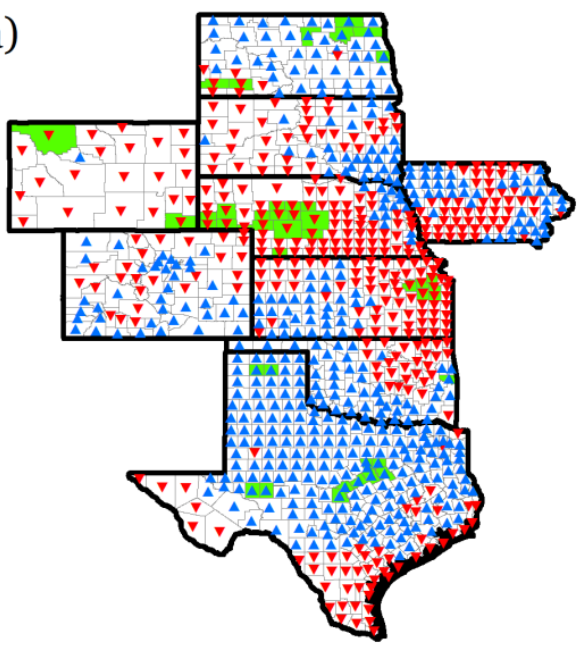

c)

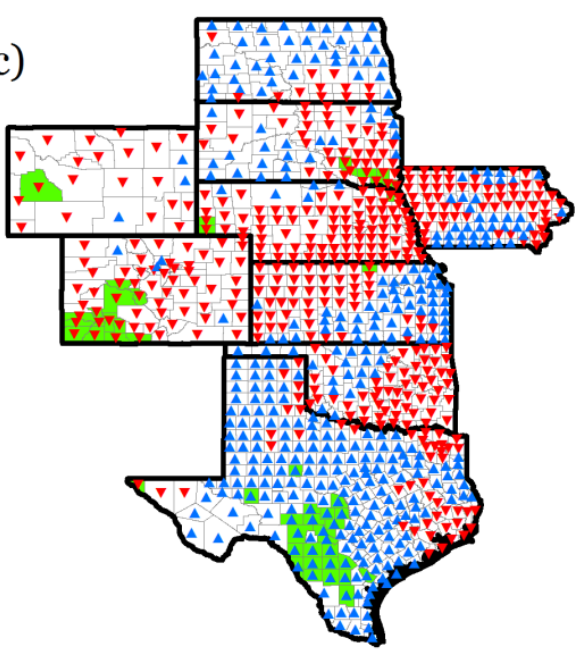

e)

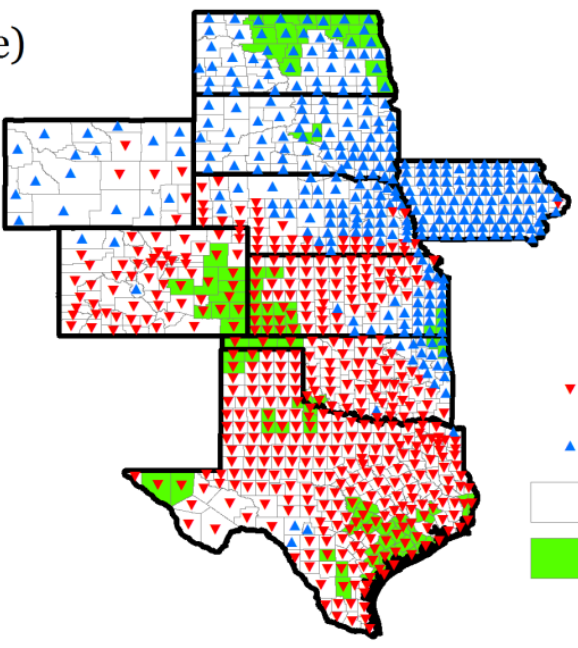

b)

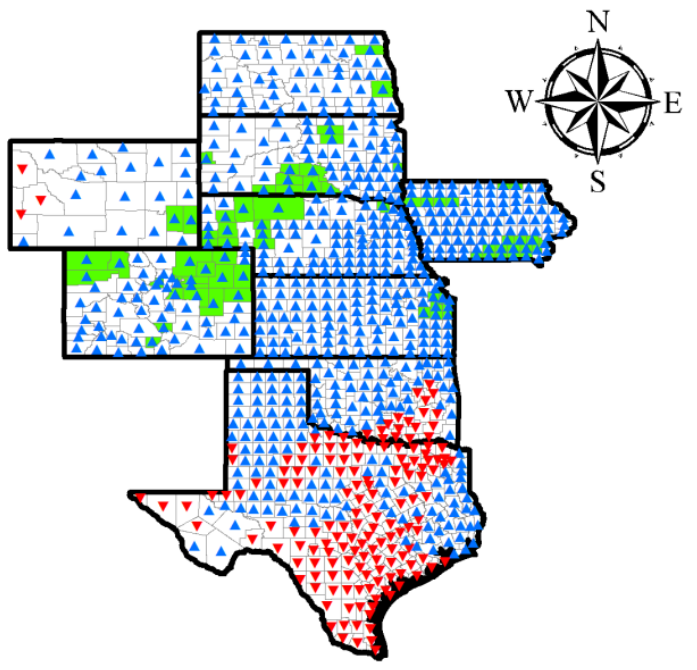

d)

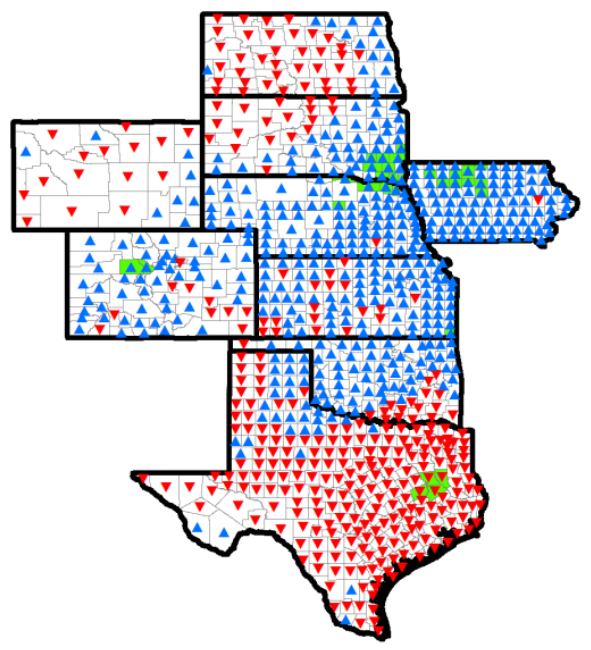

Decreasing trend

$\triangle \quad$ Increasing trend Non-significant Significant

$$
0.290 .580
$$

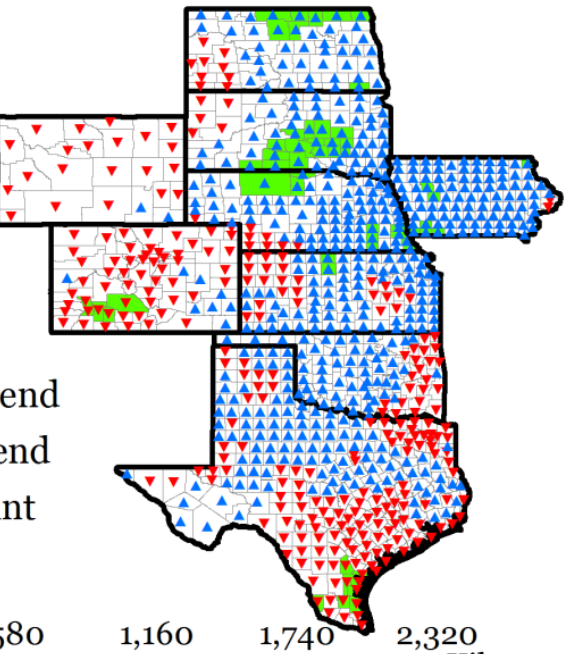

Figure 15. Spatial distribution and statistical significance of county-based trends in aridity index for a) January b) February, c) March, d) April, e) May, f) June, g) July, h) August, i) September, j) October, k) November, 1) December. 
g)

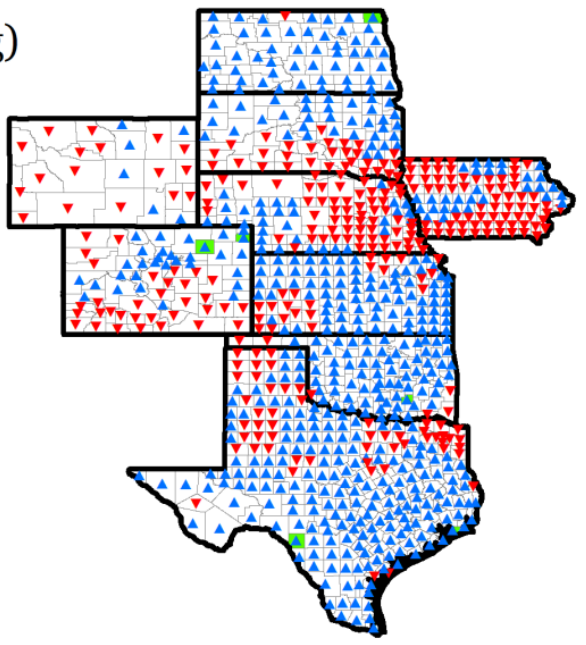

i)

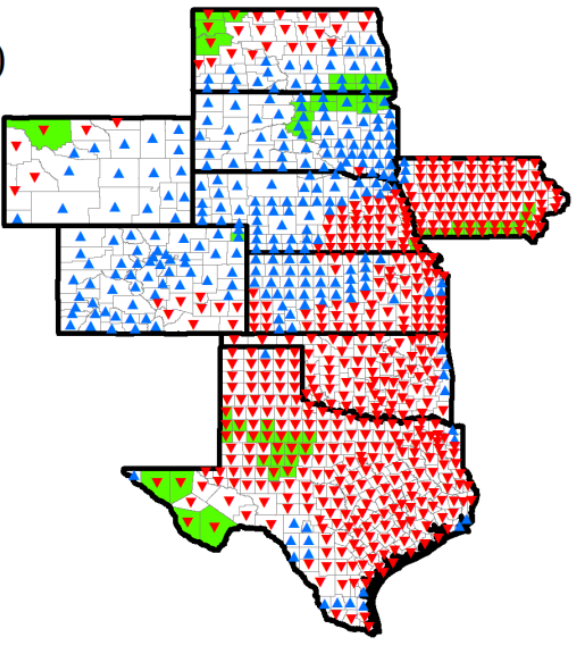

k)

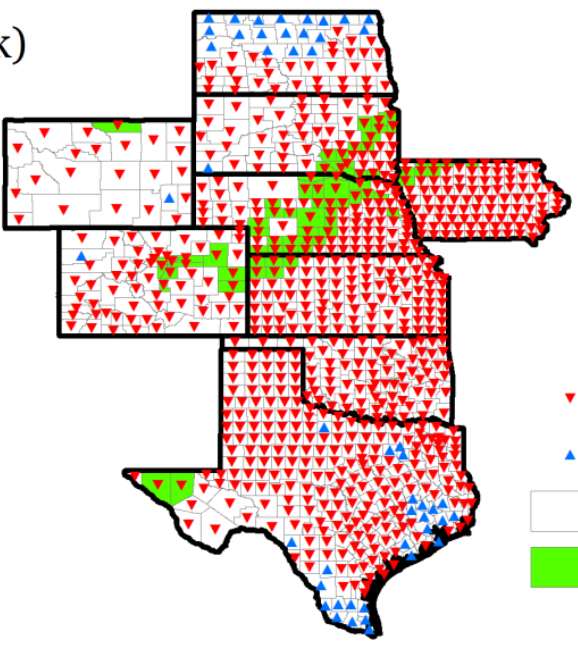

h)
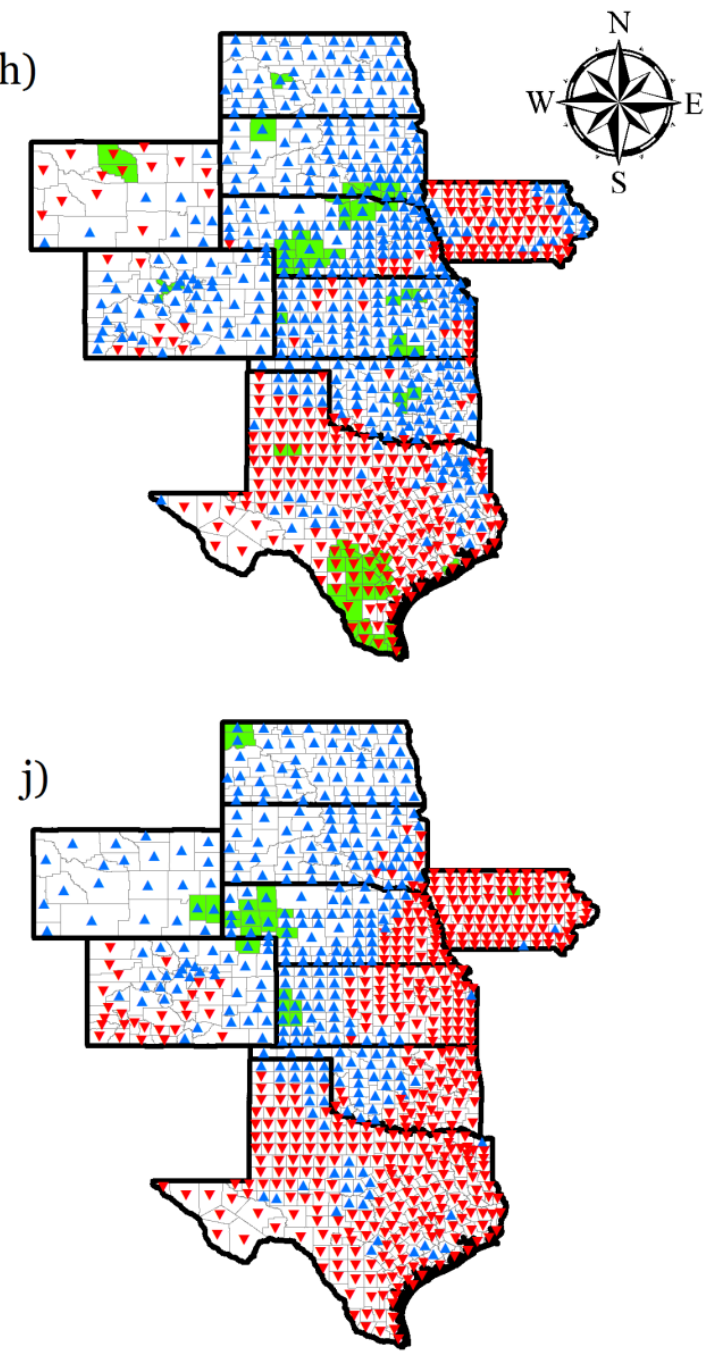

1)

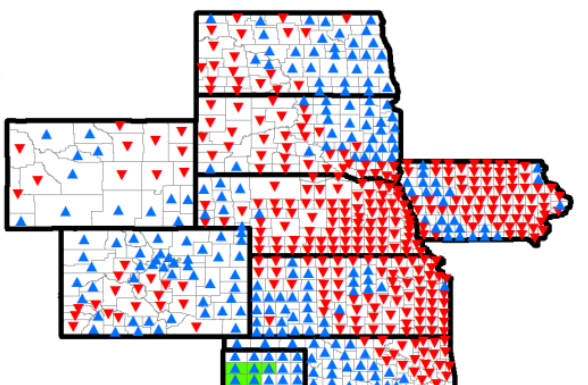

- Decreasing trend

$\triangle \quad$ Increasing trend

Non-significant

Significant

o 290580

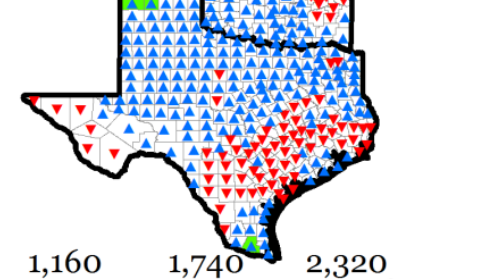

Kilometers

Figure 15 (cont.). Spatial distribution and statistical significance of county-based trends in aridity index for a) January b) February, c) March, d) April, e) May, f) June, g) July, h) August, i) September, j) October, k) November, 1) December. 